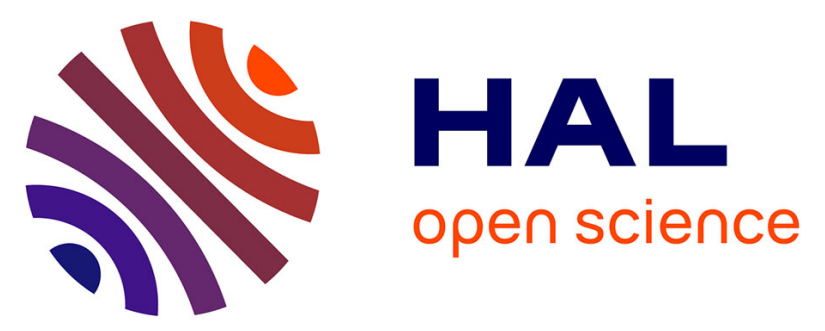

\title{
Photon assisted-inversion of majority charge carriers in molecular semiconductors-based organic heterojunctions
}

Gracia Loma Kikobo, Abhishek Kumar, Vaibhav Vibhu, Seydou Ouedraogo, Alix Deshotel, Mickaël Mateos, Rita Meunier-Prest, Marcel Bouvet

\section{- To cite this version:}

Gracia Loma Kikobo, Abhishek Kumar, Vaibhav Vibhu, Seydou Ouedraogo, Alix Deshotel, et al.. Photon assisted-inversion of majority charge carriers in molecular semiconductors-based organic heterojunctions. Journal of Materials Chemistry C, 2021, 9 (14), pp.5008-5020. 10.1039/d0tc05828a . hal-03364458

\section{HAL Id: hal-03364458 \\ https://hal.science/hal-03364458}

Submitted on 4 Oct 2021

HAL is a multi-disciplinary open access archive for the deposit and dissemination of scientific research documents, whether they are published or not. The documents may come from teaching and research institutions in France or abroad, or from public or private research centers.
L'archive ouverte pluridisciplinaire HAL, est destinée au dépôt et à la diffusion de documents scientifiques de niveau recherche, publiés ou non, émanant des établissements d'enseignement et de recherche français ou étrangers, des laboratoires publics ou privés. 


\section{Graphical Abstract}

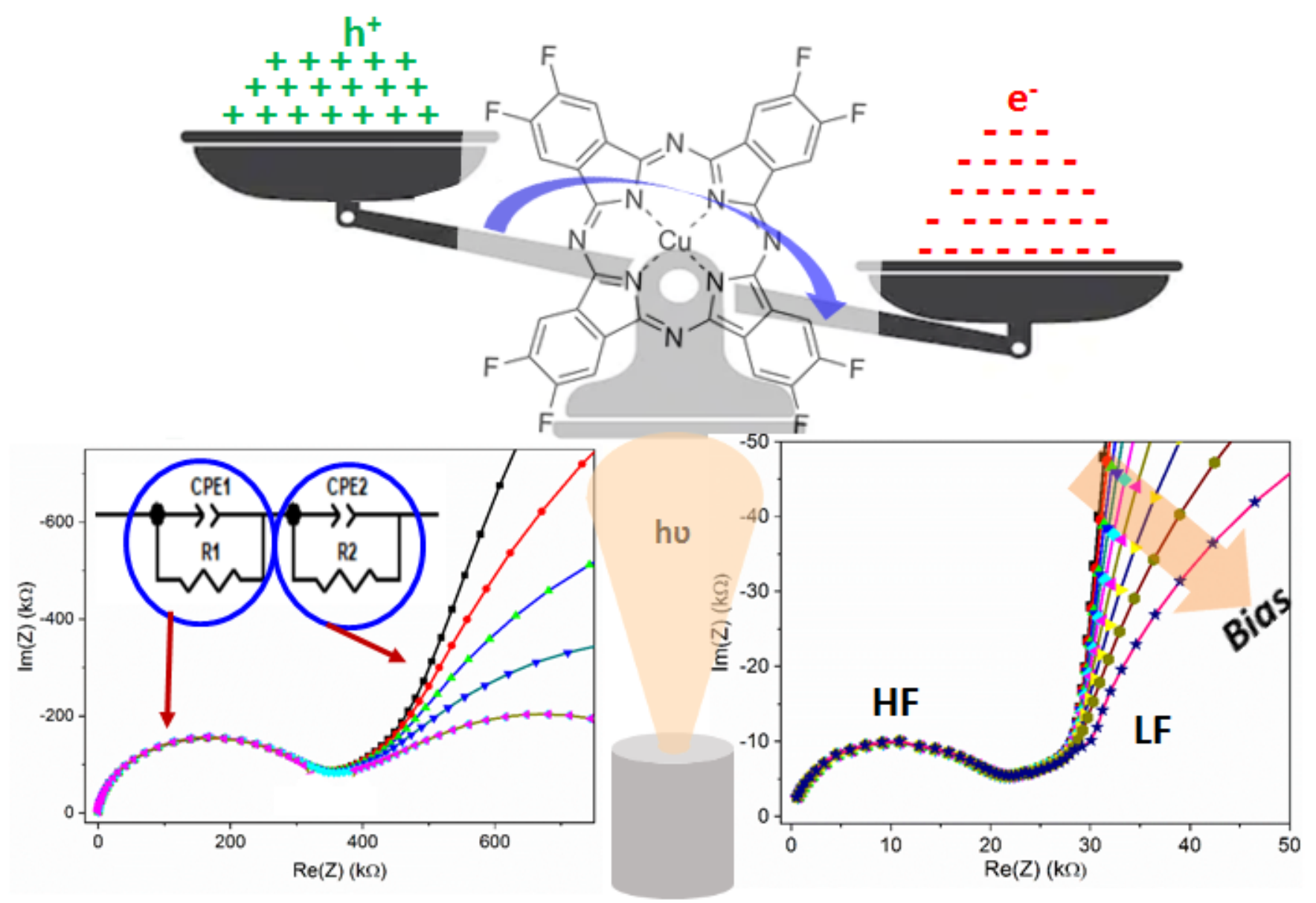




\title{
Photon assisted-inversion of majority charge carriers in molecular
}

\section{semiconductors-based organic heterojunctions}

\begin{abstract}
Gracia Loma Kikobo $^{a}$, Abhishek Kumar ${ }^{a}$, Vaibhav Vibhu $^{b}$, Seydou Ouedraogo ${ }^{\text {a,c }}$, Alix Deshotel ${ }^{a}$, Mickaël Mateos ${ }^{a+}$, Rita Meunier-Prest ${ }^{a}$ and Marcel Bouvet ${ }^{a *}$

Ambipolar molecular materials hold great promises as a building block of next generation highly efficient, less complex and low cost electronics devices. In this endeavor, the present work reports the fabrication of organic heterojunction devices based on halogenated copper Phthalocyanines (CuPc) and lutetium bisphthalocyanine ( LuPc$\left._{2}\right)$ bilayer, investigates their structural and electrical properties and probes the ambipolar behavior by ammonia sensing. Microstructural analysis of the heterostructure thin films revealed compact and semicrystalline organization, depending on the number of halogen substituents in CuPc. The heterojunction devices reveal a non-linear I(V) characteristics associated with interfacial energy barrier which is tuned by the number and type of halogen substituents. The devices behavior towards $\mathrm{NH}_{3}$ exposure revealed $n$-type, $p$-type and ambipolar transport depending on 16, 0 and 8 fluorine substituents, respectively present in CuPc component of the heterostructure, demonstrating a correlation between electronic effects of substituents to the thin film electrical properties. The trigger of ambipolar transport regime in the heterojunction device is the visible light, such that device conduction channel is dominated by holes in the dark and electrons under illumination. In depth charge transport studies by impedance spectroscopy explains the device electrical behavior and highlights the important role played by the interface in the heterostructures. Different charge transport parameters are extracted by fitting of the experimental Nyquist curves, analysis of those confirm the presence of bulk and interfacial transport and provides an interpretation of the observed ambipolarity.
\end{abstract}

\section{Introduction}

Molecular semiconductors displaying ambipolar charge transport ${ }^{1}$ have been the research focus in recent years in the field of organic electronics. Such materials have demonstrated high prospects in CMOS-like inverters in which $n$-type and $p$ type transistors can be replaced by one ambipolar transistor, enabling simpler circuit designs, reducing the power dissipation and improving the switching efficiency, ${ }^{2,3}$ as well as in high density data storage, ${ }^{4}$ photonic memory ${ }^{5}$ and artificial synapses. ${ }^{6}$ Chemical sensors are another widely researched area inspiring numerous studies on organic semiconductors, but only a few deal with ambipolar carrier transport despite of their advantages of dual mode operation (device operating at negative and positive bias), bias-dependent selectivity, ${ }^{7}$ miniaturized multiplexed detection platforms and lower fabrication cost compared to their inorganic counterparts. ${ }^{8,9}$

In particular, organic macrocycles like metal phthalocyanines (MPcs) are versatile molecular semiconductors in which the dynamics of the charge carriers $\left(\mathrm{e}^{-}\right.$and $\left.\mathrm{h}^{+}\right)$upon chemical doping by redox gases, such as nitrogen dioxide, ammonia and ozone, can be exploited for chemosensing studies. ${ }^{10-12} \mathrm{MPc}$ materials manifested a strong correlation between molecular level electronic properties with thin film electrical behaviour and thus the charge carriers in devices based on them can be effectively tuned by molecular engineering by either changing peripheral ligands or central metal atom. ${ }^{13,14}$ For example, chemiresistors based on p-type transition metal MPc displayed unipolar carrier transport in redox gases sensing, depicting current increase under electron acceptor gases and current decrease under donor gases. ${ }^{15,} 16$ On the other hand, chemiresistors based on substituted lanthanide complexes of double or triple decker phthalocyanine exhibited current increase under $\mathrm{NO}_{2}$ as well as for $\mathrm{NH}_{3}$ exposure, clearly demonstrating ambipolar chemosensing regime. ${ }^{17,} 18$ The carrier transport modulation in MPc by changing the peripheral ligands, among fluoro, alkoxy and ester, and its implication on $\mathrm{NH}_{3}$ sensing were exemplified in our recent works based on an organic heterojunction device. ${ }^{19}$ Moreover, the phenoxy and naphthoxy substitution in europium tripledecker phthalocyanine complexes generated very high, similar $\mathrm{e}^{-}$and $\mathrm{h}^{+}$carriers mobilities, both above $1 \mathrm{~cm}^{2} \mathrm{~V}^{-1} \mathrm{~s}^{-1}$ in OFET devices and thus demonstrated air stable ambipolar carriers transport. ${ }^{20,21}$ However, it must be noted that all the materials having both $\mathrm{p}$ - and $\mathrm{n}$-channels did not reveal ambipolar sensing behaviour because of large difference of $\mathrm{e}^{-}$and $\mathrm{h}^{+}$ concentrations or the lack of a suitable trigger (an external stimulus) to shift the equilibrium concentration of either charge carriers $\left(\mathrm{e}^{-}\right.$and $\left.\mathrm{h}^{+}\right)$. An example is a europium triple decker phthalocyanine complex bearing thiohexyl groups, $\mathrm{Eu}_{2}\left[\mathrm{Pc}(\mathrm{S}-\mathrm{hexyl})_{8}\right]_{3}$, in chemiresistor configuration, exhibited $\mathrm{n}$ type polarity with a current decrease under $\mathrm{NO}_{2}$, but was insensitive to $\mathrm{NH}_{3}$ and $\mathrm{H}_{2} \mathrm{~S}^{22}$

Therefore, to achieve an ambipolar transport regime in organic electronics devices including gas sensors, there are two main challenges; tuning the $\mathrm{e}^{-}$and $\mathrm{h}^{+}$concentrations in the device near equilibrium to a sufficiently large level and an efficient trigger for the majority charge carrier inversion. To obtain high $\mathrm{e}^{-}$and $\mathrm{h}^{+}$densities in equilibrium in molecular semiconductor like MPc, an appropriate combination of electron accepting and electron donating substituents are grafted and metal centers of different electron affinities are used. However, by 
adopting such strategy, only a few lanthanide phthalocyanines ( $\mathrm{LuPC}_{2}$ and $\mathrm{Eu}_{2} \mathrm{PC}_{3}$ ) were synthesized possessing the sufficiently large $\mathrm{e}^{-}$and $\mathrm{h}^{+}$densities in equilibrium comparable to unipolar MPcs, and a narrow band gap such that their HOMO and LUMO levels aligned with the electrodes workfunction to facilitate charges injection and reception by the electrodes. Since majority of MPcs are wide band gap semiconductors with low carriers mobility, a bilayer of $n$-type and $p$-type MPc heterostructure is an alternative in which each component's workfunction could align with the electrode's workfunction, facilitating low-energy charge transfer at the electrode-MPc interface. $^{23,} 24$ Moreover, the associated organic heterojunction effects enhance the carriers' mobility at the interface by the accumulation of $\mathrm{e}^{-}$and $\mathrm{h}^{+}$, thereby filling the traps and transforming a discrete hopping into a band like transport. $^{25,26}$ In fact, the bilayer thin films of $\mathrm{CuPc} / \mathrm{Cu}\left(\mathrm{F}_{16} \mathrm{Pc}\right)$ heterojunction have been extensively investigated in OFET like configuration and have shown 8-order of magnitude higher conductivity than individual MPc films and ambipolar carrier transport, ${ }^{27,28}$ but none of these were investigated for gas sensing applications. Also, there are only a few reports on external trigger to invert the majority charge carriers in gas sensors. In OFET-based gas sensors, gate voltage modulation and chemical doping from analyte gases are commonly used to switch between $\mathrm{e}^{-}$or $\mathrm{h}^{+}$conduction channels. ${ }^{7}$ An ambipolar OFET operating alternatively in $n$-channel and $p$-channel modes based on diketopyrrole was reported to selectively detect different isomers of xylene vapours depending on the applied gate voltage. ${ }^{29}$ The role of relative humidity $(\mathrm{rh})$ in the sensors ambient environment as an external trigger for majority carrier inversion was demonstrated in our studies on a MPcs bilayer heterojunction, which turns from a p-type to a n-type device on changing the rh value from $30 \%$ to $70 \% .{ }^{30}$ Elsewhere, the chemical doping from $\mathrm{NO}_{2}$ acted as a trigger to reverse conduction channel polarity in inorganic $p$-n junction diode based on tungsten disulfide. ${ }^{31}$ Despite these advancements, availability of a universal trigger for majority carrier inversion, which can be applied in any device configuration with a minimum instrumentational complexity, is a pertaining challenge, limiting the wide scale use of semiconducting materials with bipolar carriers transport in gas sensors.

Herein, MPcs based bilayer heterojunctions consisting of $\mathrm{LuPc}_{2}$ as a top layer and substituted CuPc as a sublayer incorporated in an original device configuration, recently developed and patented by $\mathrm{us}^{32}$ have been investigated for ambipolar $\mathrm{NH}_{3}$ sensing by using visible light as an external trigger for device polarity inversion. Our strategies involve peripheral substitution of variable numbers of fluorine or chlorine substituents in CuPc to achieve equilibrium $\mathrm{e}^{-}$and $\mathrm{h}^{+}$ concentrations, optimizing the organic heterojunction effects in order to enhance the bipolar carrier mobility and using lowenergy photons to switch between $\mathrm{e}^{-}$and $\mathrm{h}^{+}$in the device conduction channels. It is well known that CuPc and its perfluorinated analogue are p-type and n-type semiconductors, respectively, in air. ${ }^{33}$ Therefore, partially fluorinated $\mathrm{CuPc}$, like $\mathrm{Cu}\left(\mathrm{F}_{8} \mathrm{Pc}\right)$, has a high prospect of possessing bipolar carrier mobility. ${ }^{34}$ Accordingly, heterojunction devices based on $\mathrm{CuPc}, \mathrm{Cu}\left(\mathrm{F}_{8} \mathrm{Pc}\right), \mathrm{Cu}\left(\mathrm{Cl}_{8} \mathrm{Pc}\right)$ and $\mathrm{Cu}\left(\mathrm{F}_{16} \mathrm{PC}\right)$ as a sublayer and $\mathrm{LuPC}_{2}$ have been investigated to probe the evolution of ambipolar transport. Different MPc thin films and related heterostructures have been characterized by $X R D, E D X$ and SEM to investigate structure, chemical purity and morphologies of the thin films and nature of interfaces. Finally, in depth charge transport studies by impedance spectroscopy in different heterostructures have been performed to assess the important role played by the interface, which has been further correlated with thin films structures and electronic effects of substituents in MPc.

\section{Results and discussion}

\section{Heterojunction device structure and characterizations}

The device configuration (Scheme 1) consisted in a bilayer heterostructure of MPc sequentially coated on ITO electrodes such that the sublayer is a relatively poor conducting CuPc or its halogenated derivatives while the top layer is the high conducting double decker $\mathrm{LuPc}_{2}$, which is an intrinsic radical semiconductor, matching its carriers density with the conventional inorganic semiconductors. ${ }^{35}$ Such a large gradient of carriers' concentration between the two layers facilitates higher charge injection across the interface and thus enhanced

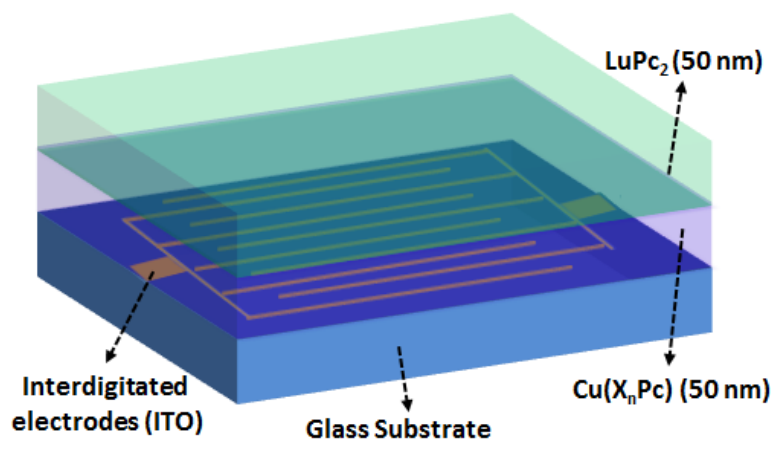

Scheme 1. Scheme of organic heterojunction device having $\mathrm{LuPc}_{2}$ as top layer and $\mathrm{Cu}\left(\mathrm{X}_{\mathrm{n}} \mathrm{Pc}\right)$ as sublayer coated on ITO electrodes. $\mathrm{X}$ refers to $\mathrm{F}, \mathrm{Cl}$ and $\mathrm{n}=0,8$ and 16.

accumulation of dipoles at the interface because of the organic heterojunction effects. ${ }^{36,37}$ Additionally, low conductivity of the sublayer minimizes the bulk transport between the electrodes and favors the transport along the interface. On the other hand, high conductivity of the top layer is preferred for redox gases sensing application because gas molecules interact on the sensors top surface and transfer $\mathrm{e}^{-}$or $\mathrm{h}^{+}$, which must be quickly transported to the interface for a faster response. Four different devices based on relatively poor conducting CuPc, $\mathrm{Cu}\left(\mathrm{F}_{16} \mathrm{Pc}\right), \mathrm{Cu}\left(\mathrm{F}_{8} \mathrm{Pc}\right)$ and $\mathrm{Cu}\left(\mathrm{Cl}_{8} \mathrm{Pc}\right)$ sublayers were fabricated.

SEM and EDX studies of MPc films Thin film microstructures and morphologies of the sub layers and the top layers strongly influence the heterostructure interface and accordingly the 
electrical properties of the heterojunction, which were studied by SEM and XRD. The SEM micrographs of different MPc thin films $(50 \mathrm{~nm})$ are shown in Fig. 1, displaying distinct morphologies as a function of halide substituents. In general, surfaces are dense with poor organization in which two different phases comprising a flat surface and grains decorating the flat surface can be noticed, which can be associated with the amorphous and crystalline packing, respectively, of the MPc molecules. However, the grains size changes with the degree of halogenation in the CuPc. Perfluorinated $\mathrm{CuPc}$ depicts the bigger grains as compared to CuPc, while $\mathrm{Cu}\left(\mathrm{F}_{8} \mathrm{Pc}\right)$ presents almost a flat morphology and grains are too small to be visualized on the micrometric scale. In fact, such trends are in agreement with previous work reporting larger crystallites in perfluorinated phthalocyanines compared to their unsubstituted counterpart, which is attributed to stronger edge-on intermolecular interactions. ${ }^{34}$, 38 Interestingly, $\mathrm{Cu}\left(\mathrm{Cl}_{8} \mathrm{Pc}\right)$ thin films present a different arrangement, consisting of relatively larger flacks instead of grains (Fig. 1e), which are of variable sizes. Such surface evolution points random agglomeration of the macrocycles which is also consistent with previous studies mentioning that higher than tetrachlorination in CuPc produces mainly an amorphous film. ${ }^{39}$ LuPc $_{2}$ thin films also present a highly dense structure over that a few bigger size grains are randomly distributed. The dense packing of $\mathrm{LuPc}_{2}$ in thin film is advantageous for the heterostructure device because it is used as top layer and thus acts as a kinetic barrier against oxygen and humidity diffusion into the sublayer and thus protects the sublayer from oxidation. ${ }^{40}$ Nanometric images obtained at higher magnifications of different CuPc derivatives are shown in Fig. S1, in which crystallites are more clearly seen. Smaller, closely spaced and homogeneously distributed grains are evident in CuPc films while larger and far spaced grains are noticed in $\mathrm{Cu}\left(\mathrm{F}_{16} \mathrm{Pc}\right)$. Even the $\mathrm{Cu}\left(\mathrm{F}_{8} \mathrm{Pc}\right)$ films exhibit a few randomly distributed grains while nanometer sized flacks are visualized in $\mathrm{Cu}\left(\mathrm{Cl}_{8} \mathrm{Pc}\right)$ films.

Since MPc were coated through high vacuum sublimation, it becomes imperative to assess the chemical purity of the film because high temperature processing may be destructive to the macrocycles stability. Therefore, EDX spectra of different MPc films were recorded and are shown in Fig. 2a. In the EDX spectra of each MPc films, characteristic peaks associated with constituent elements are observed (marked in each spectrum). For example, spectral peaks corresponding to $\mathrm{K} \alpha$ band of carbon $(0.27 \mathrm{eV})$, nitrogen $(0.39 \mathrm{eV})$ and fluorine $(0.67 \mathrm{eV})$ atoms can be noticed. Additionally $L \alpha$ band of copper $(0.93 \mathrm{eV})$ and $\mathrm{M}$ band of lutetium (1.59 eV) are also observed. It is also evident that $\mathrm{F} / \mathrm{C}$ peak ratio is larger in $\mathrm{Cu}\left(\mathrm{F}_{16} \mathrm{PC}\right)$ than in $\mathrm{Cu}\left(\mathrm{F}_{8} \mathrm{Pc}\right)$, which is expected because of higher fluorine content. These results confirm that there is no damage to the MPc during high temperature film processing. To further establish the chemical purity of the coated MPc film over a large area, EDX mapping was performed. As depicted in Fig. S2, a homogeneous distribution of macrocycles is noticed which is expected for the thin film prepared by high vacuum sublimation.
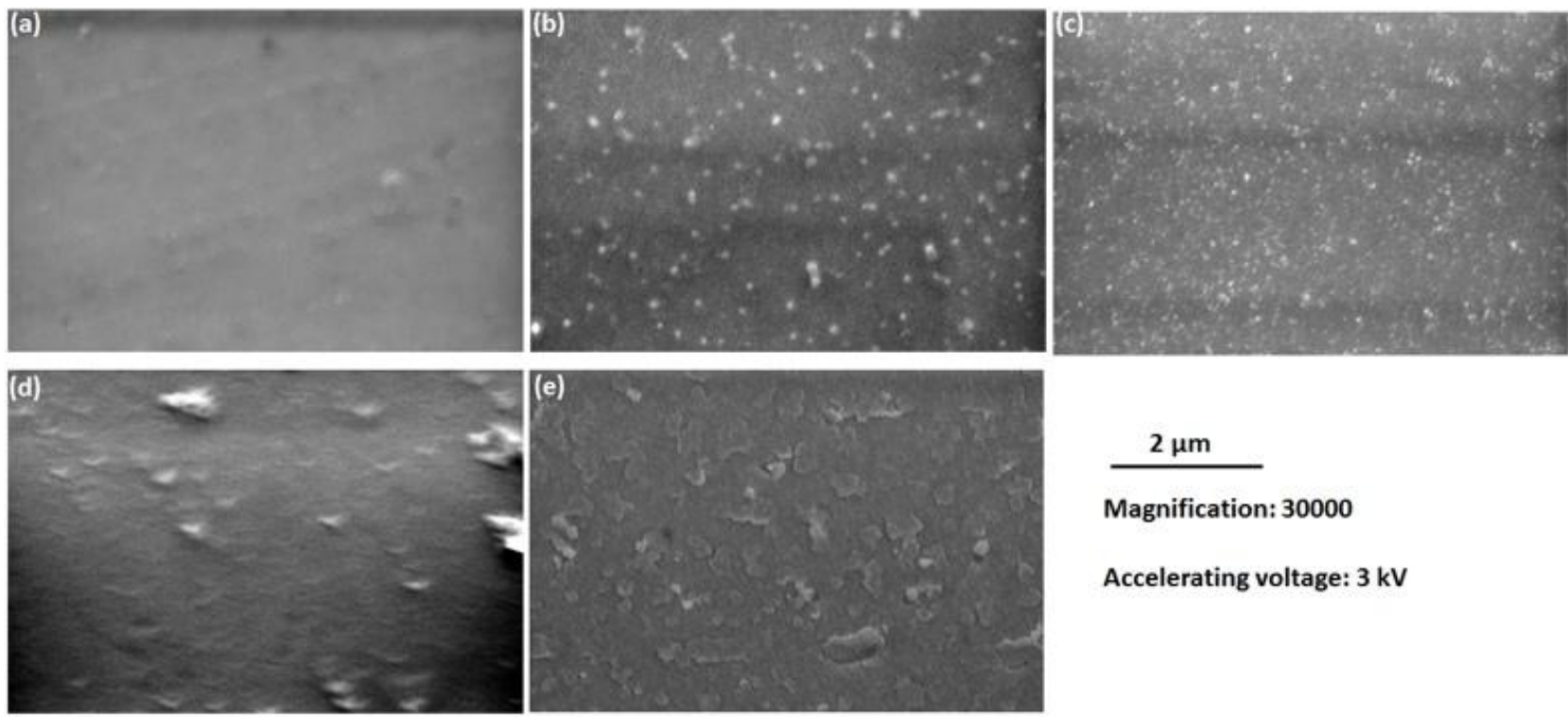

$2 \mu \mathrm{m}$

Magnification: 30000

Accelerating voltage: $3 \mathrm{kV}$

Fig. $1 \mathrm{SEM}$ images of thin films of $\mathrm{Cu}\left(\mathrm{F}_{8} \mathrm{Pc}\right)(\mathrm{a}), \mathrm{Cu}\left(\mathrm{F}_{16} \mathrm{Pc}\right)(\mathrm{b}), \mathrm{CuPc}(\mathrm{c}), \mathrm{LuPc}_{2}(\mathrm{~d})$ and $\mathrm{Cu}\left(\mathrm{Cl}_{8} \mathrm{Pc}\right)(\mathrm{e})$ coated on glass substrate at room temperature. 

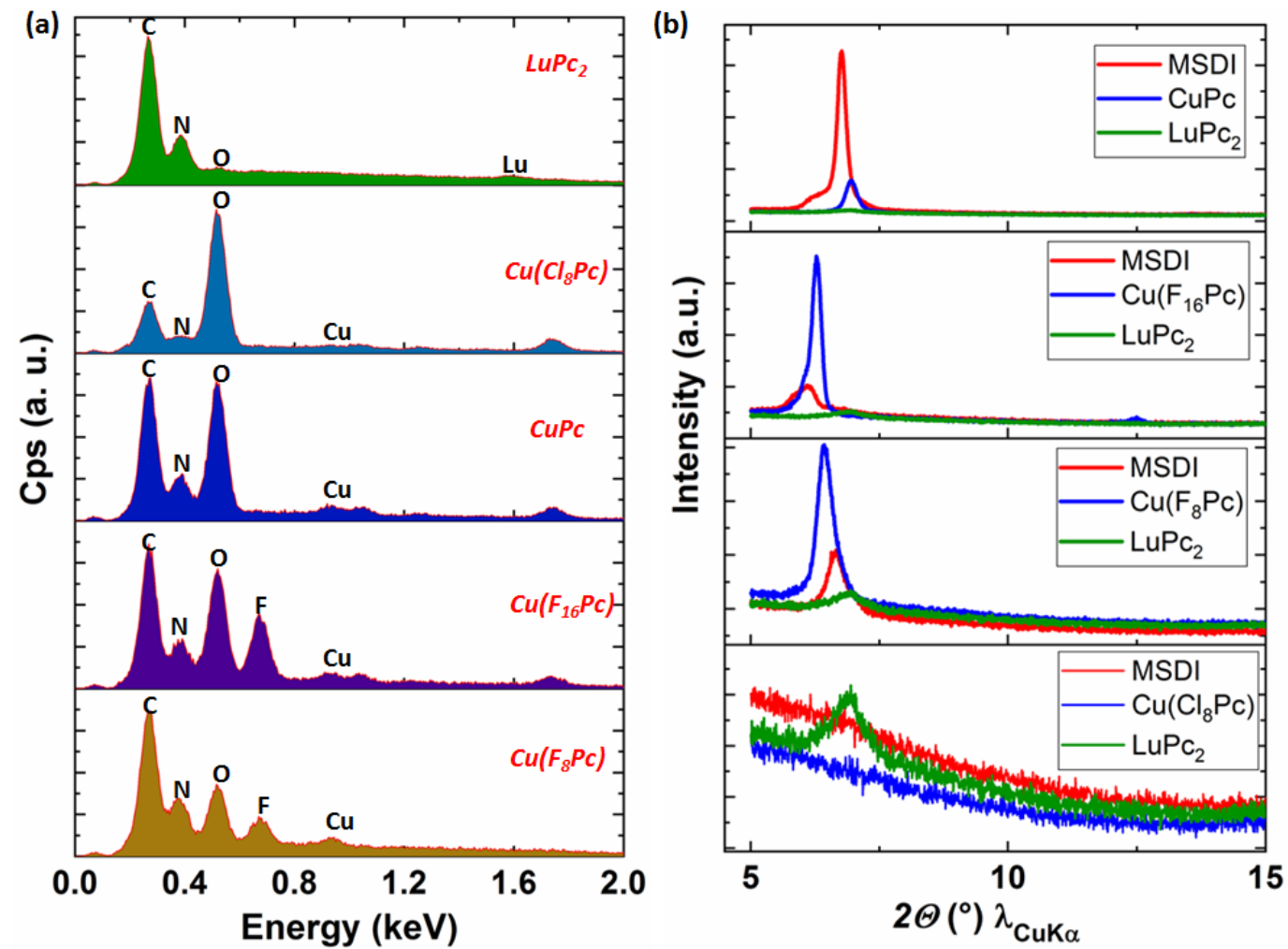

Fig. 2 EDX spectra of different MPc films coated on glass substrate (a). Comparison of XRD pattern of bilayer films with the individual films (b).

Notably, in all these EDX spectra (except LuPc$_{2}$ ), a peak associated with $\mathrm{K} \alpha$ band of oxygen is observed, which can be attributed to ITO substrate and atmospheric oxygen adsorption.

XRD studies of MPc films The crystallinity of the MPc thin film microstructures was assessed by XRD, performed at room temperature. The diffraction pattern of different bilayer heterostructures are compared with the constituents MPc in Fig. 2b, exhibiting superposition of the characteristic reflections of MPc at low diffraction angle $6-7^{\circ}$. Notably, films have low crystallinity globally as expected for the film thickness $\leq 100 \mathrm{~nm}$ for $\mathrm{MPc}^{41}$ but small pockets of locally organized structures are present also corroborated from the SEM images. Bilayer films mainly show the XRD peaks of sublayer because top layer is relatively low crystalline and adopts similar molecular orientations as of the sublayer. ${ }^{42}$ CuPc displays a diffraction peak at $6.97^{\circ}$ associated with (200) plane in its $\beta$ polymorphs which shifts to $6.78^{\circ}$ in the $\mathrm{CuPc} / \mathrm{LuPc}_{2}$ bilayer as well as increased in intensity, indicating an enlargement of the crystallites size which is further supported by lowering in FWHM (0.33 to 0.21). On the contrary, XRD peaks of heterostructures based on $\mathrm{Cu}\left(\mathrm{F}_{8} \mathrm{Pc}\right)$ ( at $6.43^{\circ}$ ) and $\mathrm{Cu}\left(\mathrm{F}_{16} \mathrm{Pc}\right)\left(\right.$ at $6.43^{\circ}$ ) exhibit decrease in the peak intensity and increase in FWHM (0.35 to 0.41 for the former and 0.25 to 0.48 for the latter), indicating decrease in the crystallites sizes from the respective sublayer. On the other hand, $\mathrm{Cu}\left(\mathrm{Cl}_{8} \mathrm{Pc}\right) / \mathrm{LuPc}_{2}$ presents almost amorphous heterostructure, which is also in agreement with the SEM images of the sublayer and the previous structural studies. ${ }^{39}$ To further understand the MPc molecular orientations in the thin film, Fullprof refinement was performed on the experimental data and different phases were identified through matching with JCPDS-ICDD database. Fig. 3 depicts the XRD patterns and their fitting over a large angle range, exhibiting a sharp peak around $6-7^{\circ}$ and a broad peak around $24-25^{\circ}$. For CuPc and its halogenated derivatives, monoclinic and triclinic unit cells are proposed in P21/n and P-1 space groups (SG), respectively (reliability factor given in ESI).

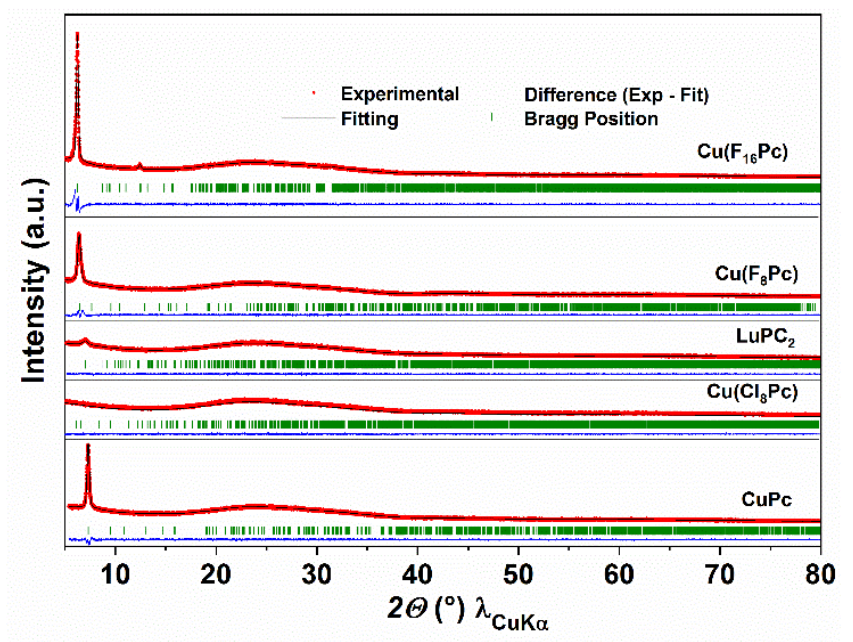


Fig. 3 XRD pattern of different MPc thin films recorded at room temperature and their

refinement by Fullprof

Table 1 Lattice parameters of studied MPc determined by FULLPROF refinement

\begin{tabular}{|c|c|c|c|c|c|c|c|c|c|}
\hline & $\mathbf{a}$ & $\mathbf{b}$ & $\mathbf{c}$ & $\boldsymbol{\alpha}$ & $\boldsymbol{\beta}$ & $\boldsymbol{v}$ & Volume & Space Group & Cell \\
\hline $\mathrm{CuPc}$ & 14.05 & 4.78 & 16.92 & 90 & 105.02 & 90 & 1097.71 & $\mathrm{P} 21 / \mathrm{n}$ & Monoclinic \\
\hline $\mathrm{CuF}_{8} \mathrm{Pc}$ & 3.71 & 11.70 & 13.81 & 85.17 & 89.93 & 83.24 & 594.23 & $\mathrm{P}-1$ & Triclinic \\
\hline $\mathrm{CuF}_{16} \mathrm{Pc}$ & 4.85 & 10.14 & 28.42 & 86.65 & 87.87 & 87.73 & 1393.70 & $\mathrm{P}-1$ & Triclinic \\
\hline $\mathrm{CuCl}_{8} \mathrm{Pc}$ & 8.02 & 13.70 & 14.74 & 81.99 & 82.01 & 80.54 & 1571.46 & $\mathrm{P}-1$ & Triclinic \\
\hline $\mathrm{LuPc}_{2}$ & 10.52 & 50.42 & 8.65 & 90 & 90 & 90 & 4593.78 & $\mathrm{P} 212121$ & Orthorhombic \\
\hline
\end{tabular}

Different lattice parameters including $a, b, c, \alpha, \beta, \gamma$ and unit cell volumes were estimated (Table 1).

In these arrangements, molecules are staked in column along the $b$-axis through strong $\pi-\pi$ intermolecular interactions in which the magnitude of $b$ represents the distance between two adjacent molecules in the column. Based on $b \sim 4.78 \mathrm{~A}^{\circ}$ for CuPc unit cells, it is evident that thin film adopts $\beta$ polymorph. ${ }^{43}$ Higher $b$ values in halogenated derivatives of CuPc are attributed to the presence of highly electronegative peripheral substituents, accumulating the negative charge at the periphery of the macrocycles which causes intermolecular repulsion. The lattice parameters $\mathrm{a}, \mathrm{c}$ and $\beta$ represent assemblies of molecular columns in the film. A highly different value of these parameters for CuPc from its halogenated derivatives can be associated with the herringbone and parallel assembly, respectively. ${ }^{43,44}$ Contrary to CuPc and its derivatives, $\mathrm{LuPC}_{2}$ thin film, which is relatively low crystalline, presents a totally different crystal structure described by orthorhombic unit cells and P21 space group. Based on the lattice parameters estimation, large spacing $\left(50.42 \mathrm{~A}^{\circ}\right)$ between two $\mathrm{LuPc}_{2}$ macrocycles in a column is obtained.

\section{Electrical properties of organic heterojunction devices}

(a)

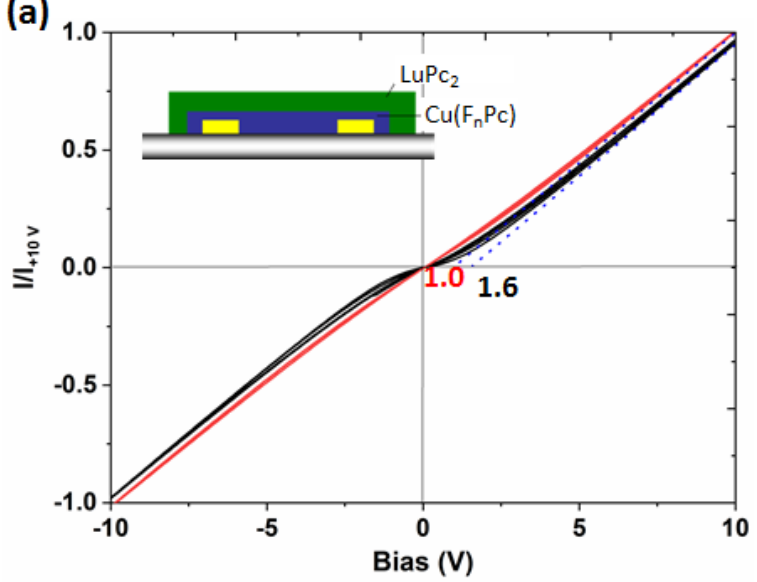

Effects of light exposure on I-V characteristics The electrical properties of the bilayer heterojunction devices were investigated by recording current in a voltage sweep from -10 $\mathrm{V}$ to $10 \mathrm{~V}$ in dark and under LED illumination (red light; $\lambda_{\max }=$ $642 \mathrm{~nm}$ ). The I(V) curves (Fig. 4) obtained in the dark and under LED exposure exhibit a typical non-linear behavior as expected for an organic heterojunction device, ${ }^{45}$ which is attributed to opposite charges accumulation at the interface creating an energy barrier. Based on the simple scheme given in the inset of Fig. 4a, evolution of $\mathrm{I}(\mathrm{V})$ curves can be formalized as follow. Because of the poor conductivity of the sublayer, current remains small at lower bias as charges injected from electrode experience high resistance. At higher bias, injected charges from the electrode have enough energy to overcome the bulk resistance of the sublayer and reach the highly conducting interface, resulting in higher current. The apparent energy barrier $U_{t h}$, deduced by extrapolating the tangent to the curve at high bias to abscissa is estimated as 6.6 $\mathrm{V}$ and $6.3 \mathrm{~V}$ for $\mathrm{Cu}\left(\mathrm{F}_{8} \mathrm{Pc}\right) / \mathrm{LuPc}_{2}$ and $1.6 \mathrm{~V}$ and $1.0 \mathrm{~V}$ for $\mathrm{Cu}\left(\mathrm{F}_{16} \mathrm{Pc}\right) / \mathrm{LuPc}_{2}$, in dark and under LED light, respectively. It is evident that energy barrier is much higher in $\mathrm{Cu}\left(\mathrm{F}_{8} \mathrm{Pc}\right) / \mathrm{LuPC}_{2}$ heterojunction than $\mathrm{Cu}\left(\mathrm{F}_{16} \mathrm{Pc}\right) / \mathrm{LuPc}_{2}$, which can be attributed to larger crystalline grains present in the latter as revealed by the XRD and SEM. Moreover higher $\mathrm{U}_{\text {th }}$ of $\mathrm{Cu}\left(\mathrm{F}_{8} \mathrm{Pc}\right) / \mathrm{LuPc}_{2}$ heterojunction

is also

(b)

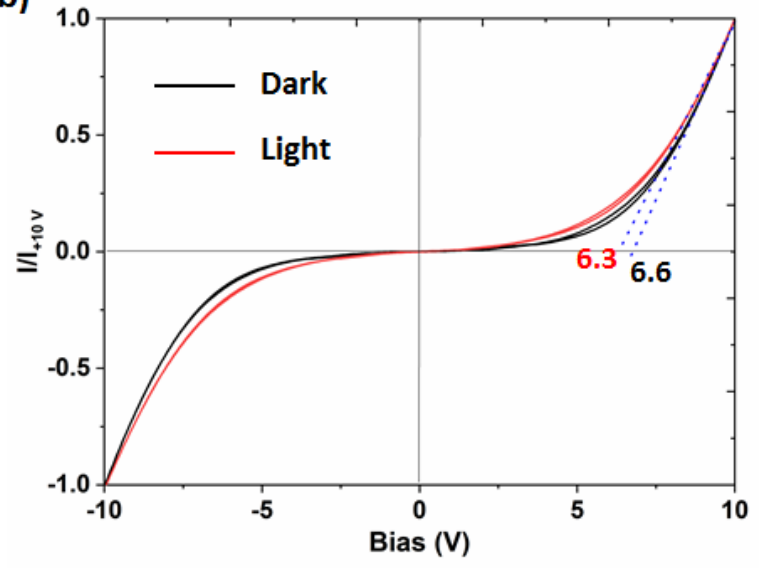

Fig. 4 Normalized I(V) characteristics of $\mathrm{LuPc}_{2} / \mathrm{Cu}\left(\mathrm{F}_{16} \mathrm{Pc}\right)(\mathrm{a})$ and $\mathrm{LuPc}_{2} / \mathrm{Cu}\left(\mathrm{F}_{8} \mathrm{Pc}\right)(\mathrm{b})$ heterojunctions, in the dark (black) and under LEDs illuminations (red). Inset in (a) represents simplified device scheme.

in agreement with the large difference in the energies of frontiers orbitals of $\mathrm{LuPc}_{2}$ and $\mathrm{Cu}\left(\mathrm{F}_{8} \mathrm{Pc}\right)$, which makes difficult for charges hopping from $\mathrm{LuPc}_{2}$ orbitals to $\mathrm{Cu}\left(\mathrm{F}_{8} \mathrm{Pc}\right)$ at the interface. ${ }^{46}$ On the other hand, LUMO level of $\mathrm{Cu}\left(\mathrm{F}_{16} \mathrm{Pc}\right)$ aligns 
well with the SOMO of $\mathrm{LuPc}_{2}$, facilitating easier charges hopping at the interface. Notably, in both heterojunctions, $U_{\text {th }}$ decreases upon light exposure, indicating that charge injection from electrode to interface becomes easier. Such behavior is explained by the generation of additional free carriers $\left(\mathrm{e}^{-}\right.$or $\mathrm{h}^{+}$), which are otherwise held in the shallow traps, upon photon exposure. ${ }^{47}$ Accordingly, device current increases under LED exposure compared to dark current for both devices. Similar measurements on other heterojunctions and $\mathrm{LuPC}_{2}$ resistor did not result in any significant change in the current values (I(V) curves shown in Fig. S3).
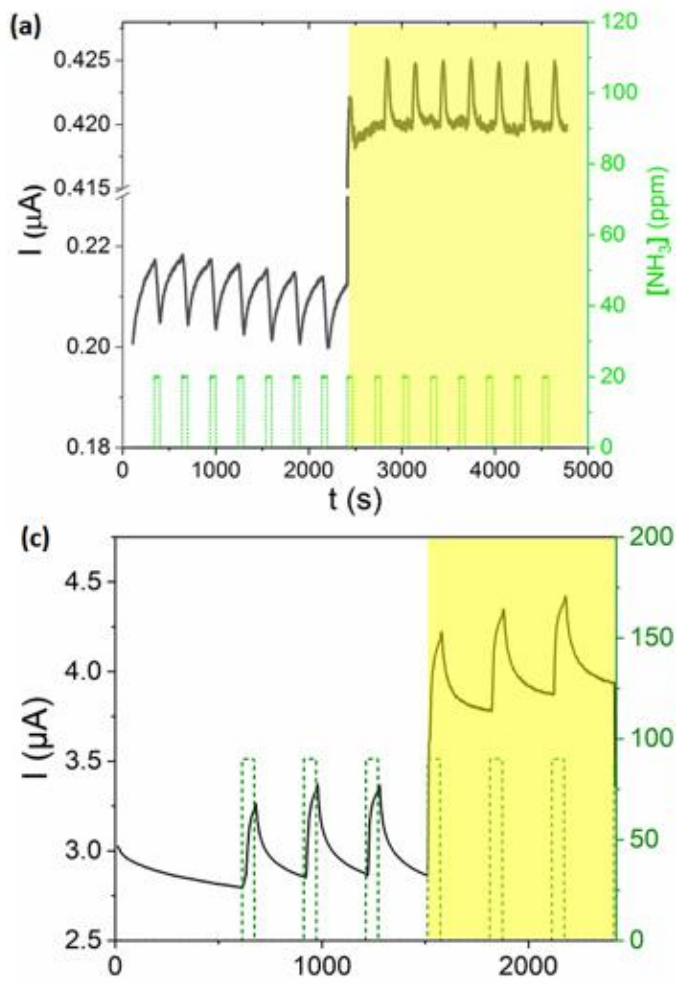

200

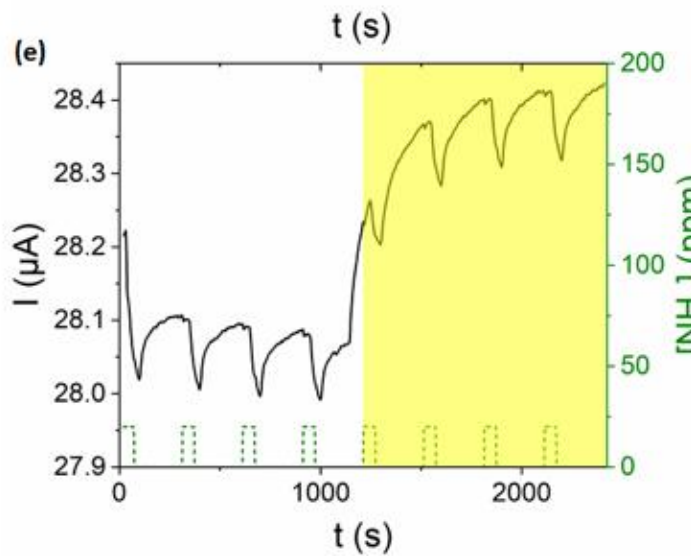

Effects of light on ammonia sensing properties of heterojunction The behavior of the heterojunction devices towards ammonia was studied by alternate exposure under 20 ppm of $\mathrm{NH}_{3}$ for $1 \mathrm{~min}$ and recovery under pure air for $4 \mathrm{~min}$ in the dark as well as under LED illumination. For $\mathrm{Cu}\left(\mathrm{F}_{8} \mathrm{Pc}\right) / \mathrm{LuPc}_{2}$ device, current decreases under $\mathrm{NH}_{3}$ exposure and increases during recovery cycle in the dark (Fig. $5 \mathrm{a}$ ) indicating the p-state of the device taking into account the electron donating nature of $\mathrm{NH}_{3}$. (b)

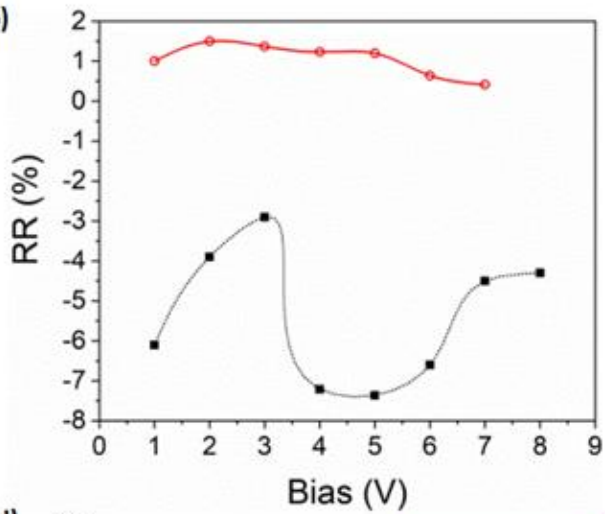

(d) 1

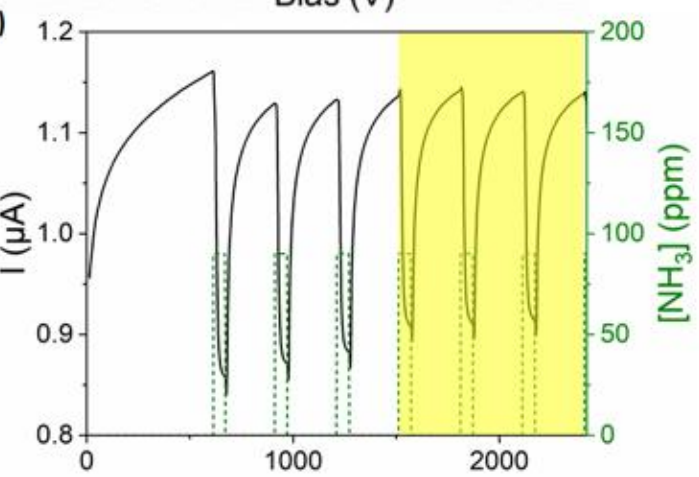

(f)

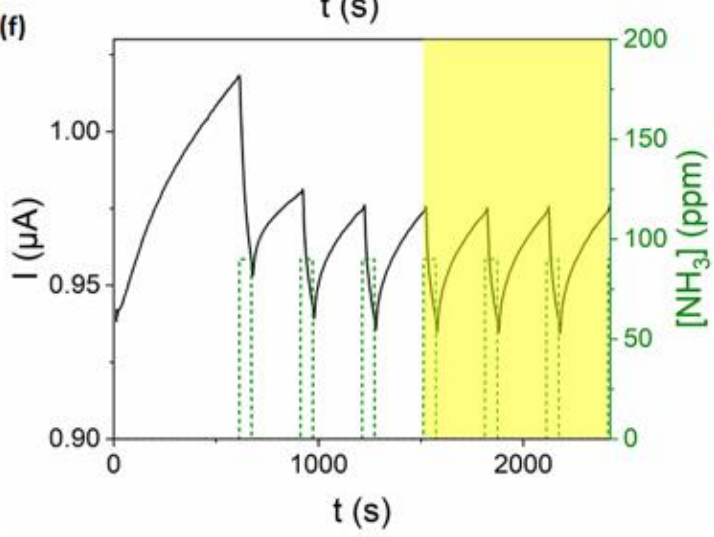

Fig. 5 Response of $\mathrm{Cu}\left(\mathrm{F}_{8} \mathrm{Pc}\right) / \mathrm{LuPc}_{2}(\mathrm{a}), \mathrm{Cu}\left(\mathrm{F}_{16} \mathrm{Pc}\right) / \mathrm{LuPc}_{2}$ (c), $\mathrm{CuPc} / \mathrm{LuPc}_{2}(\mathrm{~d}), \mathrm{Cu}\left(\mathrm{Cl}_{8} \mathrm{Pc}_{\mathrm{C}}\right) / \mathrm{LuPc}_{2}$ (e) heterojunctions and $\mathrm{LuPc}_{2}$ resistor (f) towards $\mathrm{NH}_{3}$ (20 ppm), during $1 \mathrm{~min}$ and $4 \mathrm{~min}$ of exposure and recovery cycles, respectively, at $40 \% \mathrm{rh}$, under a bias of $4 \mathrm{~V}$, in the dark and under light. Relative response of $\mathrm{Cu}\left(\mathrm{F}_{8} \mathrm{Pc}\right) / \mathrm{LuPc} \mathrm{C}_{2}$ device in dark $(\mathrm{black}$ curve) and in light (red curve) as a function of bias (b).

Interestingly, device polarity turns opposite into n-state under illumination, i.e. current increases during exposure and decreases during recovery cycle. Such polarity inversion under photon exposure, which has never been reported so far, reveals the ambipolar carrier transport regime in $\mathrm{Cu}\left(\mathrm{F}_{8} \mathrm{Pc}\right) / \mathrm{LuPc}_{2}$ heterojunction. Moreover, the device baseline 
current under its $\mathrm{n}$-state (ca. $0.42 \mu \mathrm{A}$ ) is approximately twice as observed in its p-state (ca. $0.22 \mu \mathrm{A}$ ) operation, which can be attributed to the photogeneration of additional electrons. Notably, this phenomenon was observed in a broad range of bias voltage (1-8 V), and the device exhibited $n$-state and $p$ state under light and in dark, respectively, as illustrated by the positive relative response under light and negative relative response in dark (Fig. 5b). Therefore, it can be inferred that ambipolar transport is independent of bias voltage and depends only on light exposure in $\mathrm{Cu}\left(\mathrm{F}_{8} \mathrm{Pc}\right) / \mathrm{LuPc}_{2}$ device.

The relative response (RR) as defined in equation (1) varied between $0.5 \%$ and $1.5 \%$ under illumination and between $-3 \%$ and $-7 \%$ in the dark, depending on the applied bias. The maximum RR value was estimated at 4 and $5 \mathrm{~V}$ in the dark and further decreases at higher bias because the contribution of device background current becomes much higher than the changes induced by $\mathrm{NH}_{3}$. On the contrary, below $3 \mathrm{~V}$, the RR value increases due to a smaller device background current $\left(\mathrm{I}_{\text {air }}\right)$. Under illumination, the ratio between maximum and minimum RR values is 3 , with a maximum response between 2 and $5 \mathrm{~V}$. We already reported such dependence of RR on the bias, in the dark, for a n-type unipolar bilayer heterojunction based on perylene derivatives as sublayer and $\mathrm{LuPc}_{2}$ top layer. $^{48}$

$\operatorname{RR}(\%)=\frac{I_{\mathrm{NH} 3}-I_{\text {air }}}{I_{\text {air }}} \times 100$

Contrary to the photon exposure, extended exposure to $\mathrm{NH}_{3}$ under humid atmosphere turns the device permanently into the $\mathrm{n}$-state, i.e. with positive response in the dark and under illumination (Fig. S4). Finally, it was possible to come back to the p-type state by heating at $150{ }^{\circ} \mathrm{C}$ under primary vacuum for $8 \mathrm{~h}$.

The effect of photoexcitation and its implication on $\mathrm{NH}_{3}$ response was also studied on other heterojunction devices as well as $\mathrm{LuPc}_{2}$ resistor. Contrary to heterojunction based on $\mathrm{Cu}\left(\mathrm{F}_{8} \mathrm{Pc}\right)$, no ambipolarity was observed in $\mathrm{NH}_{3}$ response under exposure to photons for other devices. A current increase upon $\mathrm{NH}_{3}$ exposure while decrease during clean air recovery is noted for $\mathrm{Cu}\left(\mathrm{F}_{16} \mathrm{Pc}\right) / \mathrm{LuPC}_{2}$ (Fig. $5 \mathrm{C}$ ) heterojunction and viceversa for $\mathrm{CuPc} / \mathrm{LuPc}_{2}(5 \mathrm{~d}), \mathrm{Cu}\left(\mathrm{Cl}_{8} \mathrm{Pc}_{2} / \mathrm{LuPc}_{2}\right.$ (5e) and $\mathrm{LuPc}_{2}$ resistor (5f), revealing a n-type conduction channel in $\mathrm{Cu}\left(\mathrm{F}_{16} \mathrm{Pc}\right) / \mathrm{LuPC}_{2}$ while $\mathrm{p}$-type conduction channels in other devices. Notably, $\mathrm{Cu}\left(\mathrm{F}_{16} \mathrm{Pc}\right) / \mathrm{LuPc}_{2}$ and $\mathrm{Cu}\left(\mathrm{Cl}_{8} \mathrm{Pc}\right) / \mathrm{LuPc}_{2}$ devices experienced enhancement in the current under visible light illumination, while $\mathrm{CuPc} / \mathrm{LuPc}_{2}$ heterojunction and $\mathrm{LuPc}_{2}$ resistor are insensitive to light. Such behavior can be explained by the stronger heterojunction effects in $\mathrm{Cu}\left(\mathrm{F}_{16} \mathrm{Pc}\right) / \mathrm{LuPc}_{2}$ and $\mathrm{Cu}\left(\mathrm{Cl}_{8} \mathrm{Pc}\right) / \mathrm{LuPc}_{2}$ devices. On the other hand, $\mathrm{CuPc} / \mathrm{LuPc}_{2}$ has very low $U_{\text {th }}$ and charge carriers are discretely distributed in the bilayer similar to $\mathrm{LuPc}_{2}$ resistor and lacks any significant interfacial accumulation, thus the charges produced by photoexcitation have negligible effect on the device current. Therefore, the unique electronic properties of $\mathrm{Cu}\left(\mathrm{F}_{8} \mathrm{Pc}\right)$ imparted by octa-fluorination in generating optimum amount of $\mathrm{e}^{-}$and $\mathrm{h}^{+}$to display ambipolar carrier transport is highlighted. To further understand the electrical properties of these heterojunctions and in particular ambipolar behavior displayed by $\mathrm{Cu}\left(\mathrm{F}_{8} \mathrm{Pc}\right) / \mathrm{LuPc}_{2}$ device, in depth charge transport studies by impedance spectroscopy were performed.

\section{Charge transport at the heterojunction interface Different} heterojunction devices as well as $\mathrm{LuPc}_{2}$ resistors were studied by impedance spectroscopy in a broad frequency range (10 $\mathrm{Hz}-10 \mathrm{MHz}$ ) and at variable $\mathrm{DC}$ voltage in the range of $0-10 \mathrm{~V}$. The Nyquist plots of these measurements are shown in Fig. 6, exhibiting two depressed semicircles for the heterojunction devices while one semicircle for the $\mathrm{LuPc}_{2}$ resistor. Moreover, the semicircles at high frequency (HF) for heterojunction devices remain unaffected by the DC voltage variation while those at low frequency (LF) get smaller with increasing bias. Clearly, it can be confirmed based on these observations that an interfacial energy barrier exists in heterojunction devices, which decreases as a function of increasing DC bias. To extract more physical information from the Nyquist curves, they were modelled through an impedance circuit, describing the electrical nature of heterojunction devices. Since the microscopic properties of the heterostructures films are distributed owing to crystalline and amorphous phases, producing grain boundaries, organizational defects and roughness, resulting in non-smooth formation of interfaces.

Such systems can be modelled by constant phase elements $(\mathrm{CPE}){ }^{49}$ which are imperfect capacitors, for which impedance $Z_{C P E}$ is defined by equation 2 , where $Q i$ is the non-ideal capacitance, $\omega$ corresponds to frequency $(2 \pi f)$ and $\alpha$ is a coefficient varying between 0 and 1 .

$Z_{C P E_{i}}=\frac{1}{Q_{i} \times(j \omega)^{\alpha_{i}}}$

The value of $\alpha$ at 0 and 1 corresponds to CPE element as ideal resistor and capacitor, respectively. Thus, the bilayer heterojunction can be modelled as a summation of two Ri-CPEi elements in series represented by the equivalent circuit shown in the inset of Fig. $6 \mathrm{~b}$. The semicircles at $\mathrm{HF}$ are described by CPE1 and R1 circuits while those at LF are described by CPE2 and R2. As semicircles at $\mathrm{HF}$ are independent of bias, they correspond to the charge transport in the bulk while the semicircles at LF change with bias, they manifest the interfacial charge 

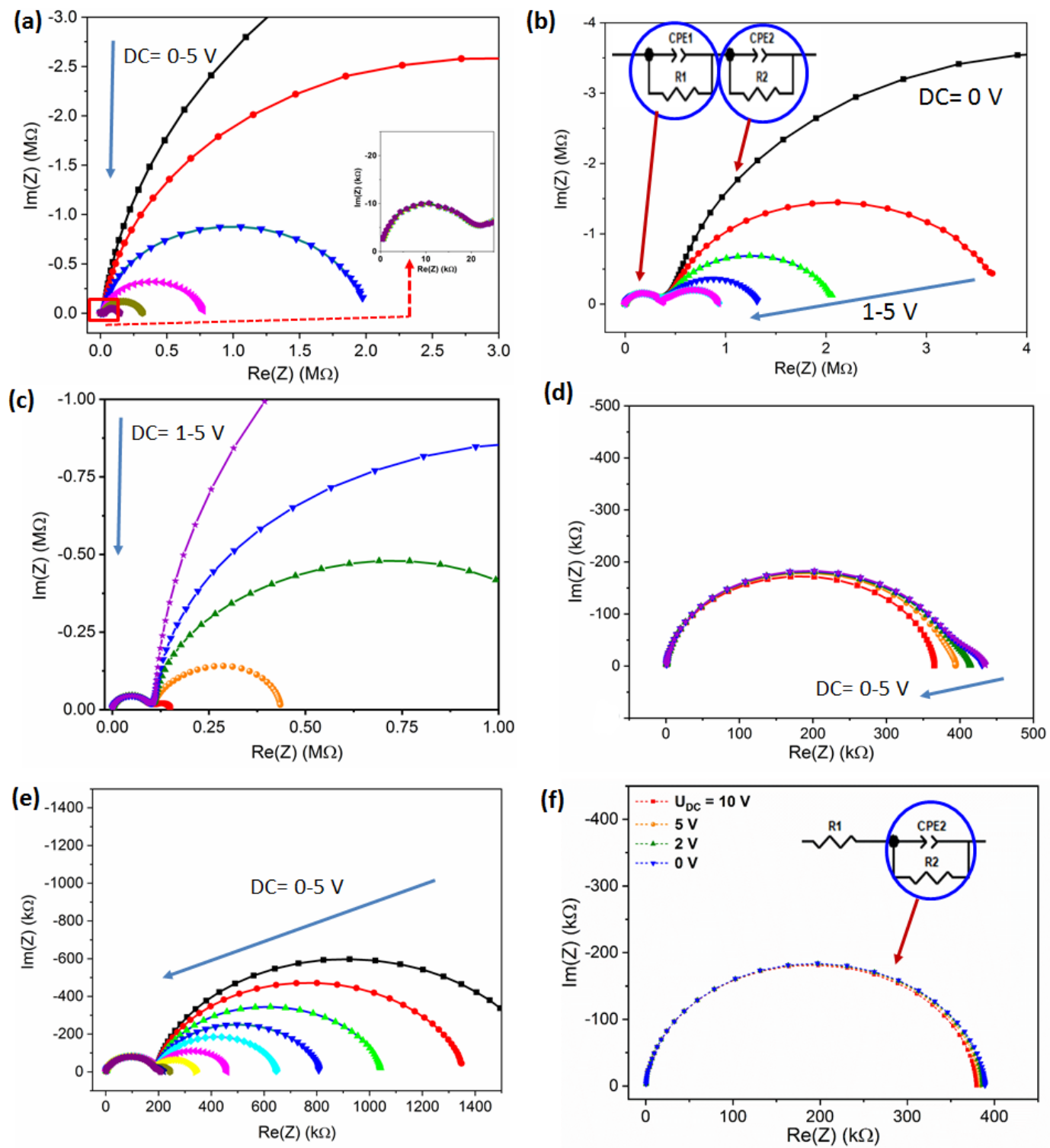

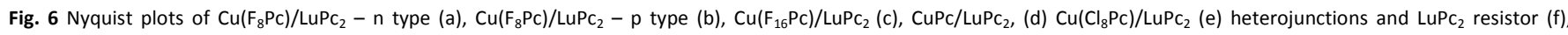
recorded at variable $\mathrm{DC}$ voltage in the range of $0-10 \mathrm{~V}$.

Based on this analogy, it can be also said that there is only bulk charge transport in $\mathrm{LuPc}_{2}$ resistor as only one semicircle independent of bias is present in its Nyquist plots. To further correlate Nyquist semicircles with the charge transport in the device, $\alpha$ parameters should be analyzed. $\alpha$ represents the nonideality of the capacitive element such that $\alpha=1$ indicates an ideal capacitor or homogeneous R-CPE elements (single time constant). As semicircles get more depressed, $\alpha$ also decreases and accordingly time constants in the distributed elements increase, indicating enhancement of heterogeneity in the R-CPE elements. In other words, capacitive contribution in the device electrical output decreases and conductive contribution increases at a constant resistance. Based on the depression in the semicircles (estimated by $\operatorname{Im}(\mathrm{Z}) / \operatorname{Re}(\mathrm{Z})$ at maximum $\operatorname{Im}(\mathrm{Z})$; values plotted in Fig. S5), the ease of bulk charge transport is thus in the order of $\mathrm{Cu}\left(\mathrm{F}_{8} \mathrm{Pc}\right) / \mathrm{LuPc}_{2}-\mathrm{n}$-type $>\mathrm{Cu}\left(\mathrm{Cl}_{8} \mathrm{Pc}\right) / \mathrm{LuPc}_{2}>\mathrm{Cu}\left(\mathrm{F}_{16} \mathrm{Pc}\right) / \mathrm{LuPc}_{2}>\mathrm{Cu}\left(\mathrm{F}_{8} \mathrm{Pc}\right) / \mathrm{LuPc}_{2}-$ p-type $>\mathrm{CuPc} / \mathrm{LuPC}_{2}>\mathrm{LuPc}_{2}$.

On the other hand, depression in the semicircles at LF increases with increasing bias (Fig. S6), indicating a decrease in the $\alpha$ values and thus enhancement in the R-CPE elements heterogeneity in the device. In other words, at higher bias, injected charges from the electrodes can overcome the capacitive barrier and participate in the conduction through multitudes of interconnected R-CPE circuits. The LF semicircles collapsed as the bias increased. This occurs when the bias 
becomes higher than the threshold voltage deduced from the I(V) curves. Notably, the LF semicircles in CuPc/LuPc $c_{2}$ device is very small compared to those at $\mathrm{HF}$, which also disappear at higher bias and the Nyquist curves become similar to those of $\mathrm{LuPC}_{2}$. Such behaviour indicates the small interface effects which is completely removed at higher bias because of effectively overcoming the low energy barrier. This is attributed to the similar energies of HOMO and SOMO orbitals of $\mathrm{CuPc}$ and $\mathrm{LuPc}_{2}$, respectively, resulting in facile interorbital charges hopping. ${ }^{50}$ Different circuit parameters such as the resistances $\mathrm{R} 1$ and $\mathrm{R} 2, \alpha 1$ and $\alpha 2$ and the effective capacitances $C_{\text {eff1 }}$ and $C_{\text {eff2 }}$ (equation 3 ) were estimated through fitting of the experimental Nyquist curves and their variation with the bias are shown in Fig. 7.

$C_{e f f i}=Q_{i}^{\frac{1}{\alpha_{i}}} \cdot R_{i}^{\frac{1}{\alpha_{i}}-1}$

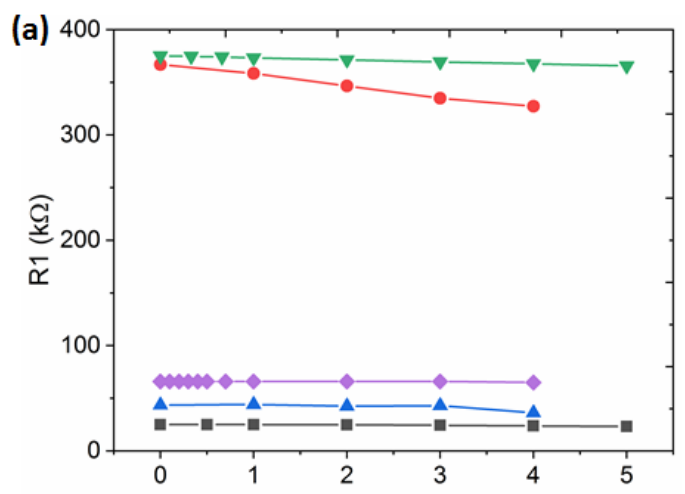

(c)
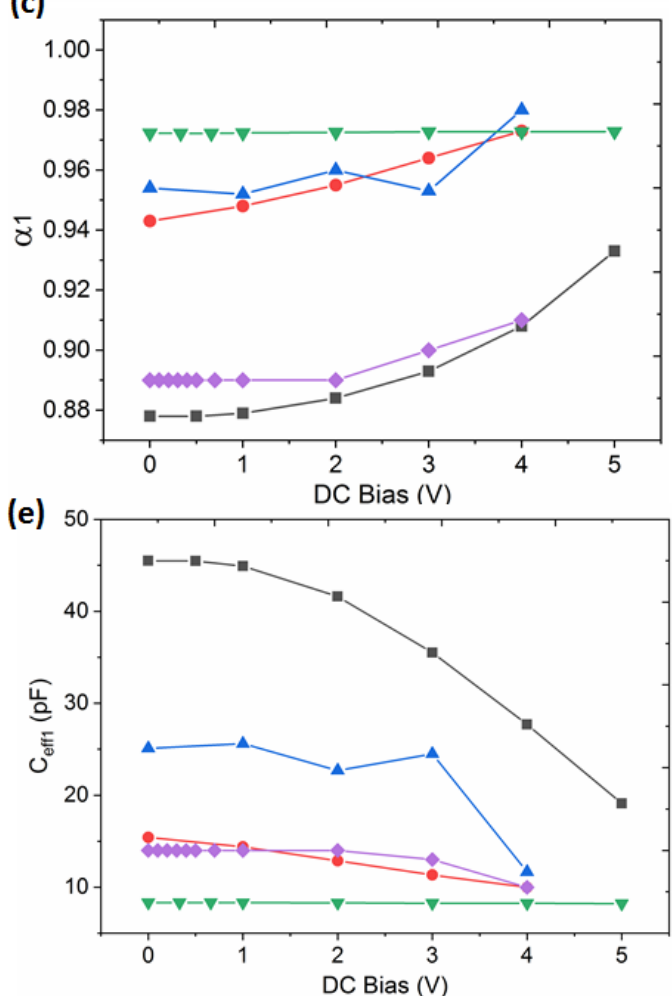

It is evident from Fig. 7a, 7c and 7e that most of the circuit parameters associated with $\mathrm{HF}$ semicircles are almost independent of the bias, which is expected for the bulk charge transport. Interestingly, $\mathrm{R} 1$ of $\mathrm{Cu}\left(\mathrm{F}_{8} \mathrm{Pc}\right) / \mathrm{LuPc}_{2}-\mathrm{n}$-type is ca. 40 times lower than $\mathrm{R} 1$ of $\mathrm{Cu}\left(\mathrm{F}_{8} \mathrm{Pc}\right) / \mathrm{LuPc}_{2}-\mathrm{p}$-type, highlighting the significant photogeneration of e- in the bulk of $\mathrm{Cu}\left(\mathrm{F}_{8} \mathrm{Pc}\right)$. The parameter R2 is very crucial to characterize the interfacial energy barrier in the heterojunction devices. As depicted in Fig. 7b, except for CuPc heterojunction, R2 is always much larger than R1 in agreement with the prevalence of the interfacial effects on the conductivity of the different materials. $\mathrm{R} 2$ is very high for $\mathrm{Cu}\left(\mathrm{F}_{8} \mathrm{Pc}\right) / \mathrm{LuPc}_{2}$ devices at low bias which is in agreement with high $U_{\text {th }}$ values determined from I$V$ curves, which decreases with increasing bias, indicating that interfacial energy barrier is overcome. On the contrary, R2 remains lower than R1 for CuPc heterojunction, indicating negligible interfacial
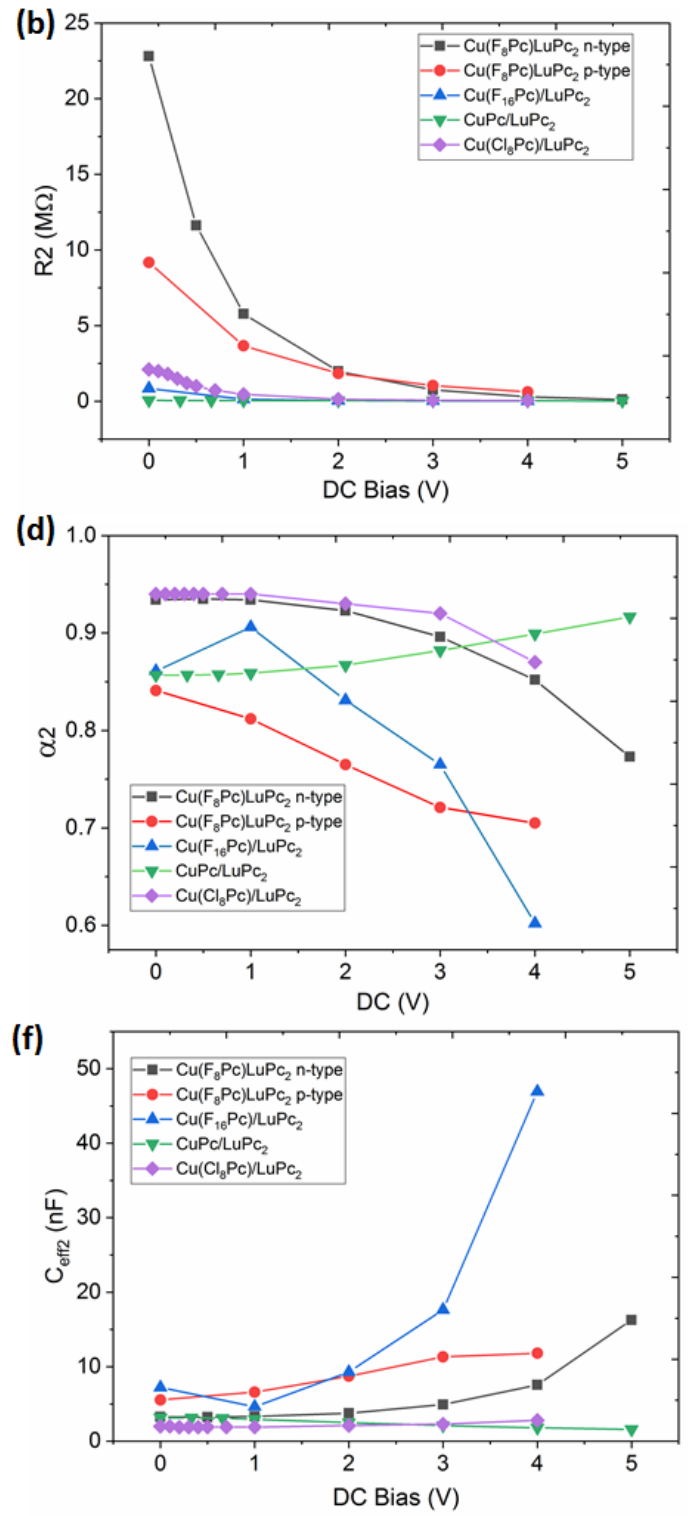
Fig. 7 Variations of equivalent circuit resistances, R1 (a) and R2 (b), $\alpha 1$ (c) and $\alpha 2$ (d) and effective capacitances Ceff1 (e) and Ceff2 (f), as a function of bias voltage (0-5 V) for different heterojunction devices.

properties in this device, as expected from the linear I-V curves. It is also worthwhile to note that, for $\mathrm{Cu}\left(\mathrm{F}_{8} \mathrm{Pc}\right) / \mathrm{LuPc}_{2}$ heterojunction, bulk conductivity is higher in its $\mathrm{n}$-mode while interfacial transport is dominant in its $\mathrm{p}$-mode.

The $\alpha 1$ value for all heterojunction devices remains close to 1 and experiences slight increase with rise in the bias voltage, indicating that R-CPE elements are close to an ideal capacitor. Therefore heterogeneity in the systems is low and decreases at higher bias. Such transport is expected in the bulk region of the heterojunction, where microstructures remain homogeneous. On the contrary, $\alpha 2$ experiences relatively large variations (Fig. 7d) and decreases as a function of bias (except $\mathrm{CuPc} / \mathrm{LuPC}_{2}$ ), such that largest change is noted for $\mathrm{Cu}\left(\mathrm{F}_{16} \mathrm{Pc}\right) / \mathrm{LuPC}_{2}$. Such behaviour reveals enhancement in the heterogeneity, which can be correlated with the higher number of the injected electrons arriving at the interface with increasing bias causing an extension of the conducting R-CPE elements. Based on the variations of $\alpha 1$ and $\alpha 2$, a broader conclusion can be drawn as the bulk charge transport remains constant (or decreases slightly) while interfacial charge transport increases with increasing bias, manifesting the key phenomenon of organic heterojunction effects.

To further confirm the interfacial charge accumulation and implication of bias voltage over it, effective capacitances of bulk and interface were estimated based on equation (3) and their variation with bias was probed. Based on the circuit elements designation, $C_{\text {eff1 }}$ corresponds to the bulk capacitance while $\mathrm{C}_{\text {eff2 }}$ is associated with the interface. At first, very low value of $C_{\text {eff1 }}$ in $\mathrm{pF}$ while relatively higher value of $\mathrm{C}_{\text {eff2 }}$ in $\mathrm{nF}$ can be remarked. Since capacitance is inversely proportional to the layer thickness, it is confirmed that interface is much thinner than the bulk, which is also a typical case of organic heterojunction effects. ${ }^{51}$ As depicted in Fig. 7e, bulk capacitance remains approximately constant for all heterojunction devices as largest change is noticed in $\mathrm{Cu}\left(\mathrm{F}_{8} \mathrm{Pc}\right) / \mathrm{LuPc}_{2}-\mathrm{n}$ type in which it decreases from $45 \mathrm{pF}$ to 20 $\mathrm{pF}$. On the other hand, interfacial capacitance $\mathrm{C}_{\text {eff2 }}$ experiences increase with the bias which can be correlated with the thinning of interface as a consequence of decrease of energy barrier. The largest and steepest rise in $\mathrm{C}_{\text {eff2 }}$ is noticed for $\mathrm{Cu}\left(\mathrm{F}_{16} \mathrm{Pc}\right) / \mathrm{LuPc}_{2}$ device from $7 \mathrm{nF}$ to $45 \mathrm{nF}$, highlighting effective overcoming of the energy barrier. It can be also noted that for $\mathrm{Cu}\left(\mathrm{F}_{8} \mathrm{Pc}\right) / \mathrm{LuPc}_{2}$ heterojunction, in its $\mathrm{p}$-type, $\mathrm{C}_{\text {eff2 }}$ is larger at all studied bias than that of $n$-type, confirming a higher interfacial energy barrier in the latter.

\section{Mechanism}

The mechanism of such photon-triggered ambipolarity and the respective energy bands position of $\mathrm{Cu}\left(\mathrm{F}_{8} \mathrm{Pc}\right)$ and $\mathrm{LuPc}_{2}$ can be explained by taking into account the $\mathrm{e}^{-}$and $\mathrm{h}^{+}$hopping between the frontier orbitals of $\mathrm{Cu}\left(\mathrm{F}_{8} \mathrm{Pc}\right)$ and $\mathrm{LuPc}_{2}$ and subsequent alignment of charges at the heterojunction interface. Some of us previously estimated the orbitals energies of these MPcs by Ultraviolet Photoelectron Spectroscopy (UPS) and based on those, $\mathrm{LuPc}_{2}$ and $\mathrm{Cu}\left(\mathrm{F}_{8} \mathrm{Pc}\right)$ orbitals can be positioned as shown in Fig. 8a. ${ }^{52,53}$ Since, the workfunction of $\mathrm{LuPC}_{2}$ is higher than $\mathrm{Cu}\left(\mathrm{F}_{8} \mathrm{Pc}\right), \mathrm{h}^{+}$transport takes place in steady state condition through path 2 , resulting in $\mathrm{h}^{+}$accumulation in $\mathrm{Cu}\left(\mathrm{F}_{8} \mathrm{Pc}\right)$ and $\mathrm{h}^{+}$depletion in $\mathrm{LuPc}_{2}$ near the interface. Such interfacial charges redistribution generates a hole accumulation/depletion heterojunction (Fig. 8b). ${ }^{54} \mathrm{NH}_{3}$ interacts mainly with top $\mathrm{LuPc}_{2}$ layer during a short exposure period and reduces the $\mathrm{h}^{+}$hopping, which is manifested by the decrease in device current.

The effect of photon exposure is however different from chemical doping from $\mathrm{NH}_{3}$ because photon can easily pass into the sublayer and excite charge carriers. In fact, the effect of photoexcitation on the carrier concentration in the top LuPc $\mathrm{C}_{2}$ layer will be negligible considering its very high carrier density and narrow band gap. But in the wide band gap and low carrier density $\mathrm{Cu}\left(\mathrm{F}_{8} \mathrm{Pc}\right)$ sublayer possessing large amount of trap states, photoexcitation can have a profound effect on the relative amount of $\mathrm{e}^{-}$and $\mathrm{h}^{+}$carriers. It is well known that oxygen adsorption on molecular materials causes their $p$-type doping by creating a lot of donor like shallow traps providing a medium for $\mathrm{h}^{+}$hopping. ${ }^{55}$ Photoexcitation desorbs the molecular oxygen ${ }^{56}$ from shallow traps near HOMO of $\mathrm{Cu}\left(\mathrm{F}_{8} \mathrm{Pc}\right)$, thereby suppressing the $\mathrm{h}^{+}$concentration and concurrently promotes $\mathrm{e}^{-}$from acceptor like shallow traps to the LUMO level, increasing the $\mathrm{e}^{-}$concentration in the sublayer. As a consequence, the Fermi level of $\mathrm{Cu}\left(\mathrm{F}_{8} \mathrm{Pc}\right)$ is lowered enough to enable charge transfer through path 1 in Figure 8a. Because of that, interfacial charges alignment takes the form of an accumulation heterojunction as shown in the Fig. 8c. The chemical doping from $\mathrm{NH}_{3}$ in the top $\mathrm{LuPc}_{2}$ layer further promotes the $\mathrm{e}^{-}$transport to the sublayer, also manifested by current increase under $\mathrm{NH}_{3}$ exposure.

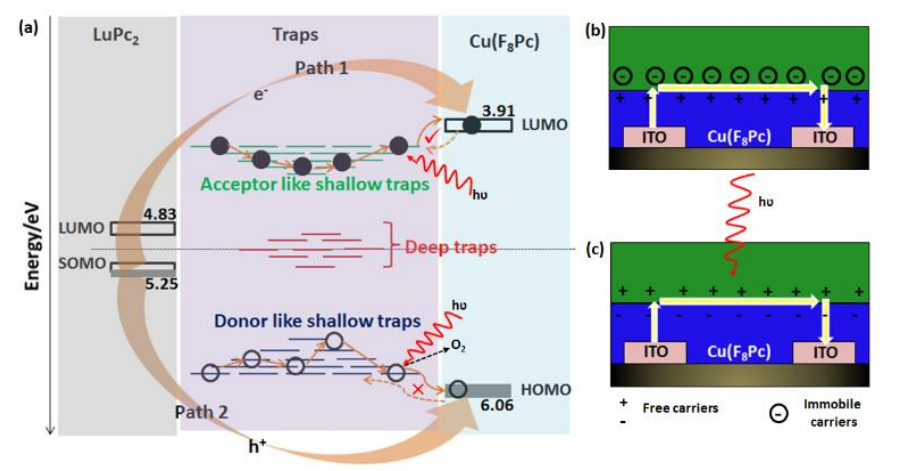

Fig. 8 The charge transport scheme between frontier orbitals and trap states in $\mathrm{Cu}\left(\mathrm{F}_{8} \mathrm{Pc}\right)$ and $\mathrm{LuPc}_{2}$ under photon exposure (a) and charges alignments at the interface in the dark (b) and in light (c). 


\section{Experimental}

\section{Reagents and materials synthesis}

The precursors for MPc synthesis including 4,5-difluoro-1,2dibromobenzene, copper cyanide, 4,5-dichlorophthalic anhydride, copper (II) acetate tetrahydrate, urea, ammonium heptamolybdate, tetrafluorophthalonitrile, copper(II) chloride, phthalonitrile, lutetium acetate trihydrate $\left(\mathrm{Lu}(\mathrm{OAC})_{3} \cdot 3 \mathrm{H}_{2} \mathrm{O}\right)$ were purchased from Sigma-Aldrich. CuPc was purchased directly from the same supplier and was used for vacuum sublimation without any purification. The solvents used in the solvothermal synthesis of phthalocyanines such as DMF, Acetone, THF, $\mathrm{CHCl}_{3}, \mathrm{H}_{2} \mathrm{SO}_{4}$ were of analytical grade and were procured from Merck. Throughout the synthesis, milli-Q ultrapure water (resistivity $\sim 18 \mathrm{M} \Omega \mathrm{cm}$ ) was used.

Synthesis of $\mathrm{Cu}\left(\mathrm{F}_{8} \mathrm{Pc}\right)$ was achieved through reaction of 4,5difluoro-1,2-dibromobenzene with copper cyanide as described in detail previously in the supplementary information file of our previous work. ${ }^{57}$ In brief, the mentioned precursors were refluxed in DMF at $150{ }^{\circ} \mathrm{C}$ for 2 hours followed by treatment with concentrated $\mathrm{H}_{2} \mathrm{SO}_{4}$ and washing with $\mathrm{CHCl}_{3}$. Finally, the products were dried at $100{ }^{\circ} \mathrm{C}$ under primary vacuum to yield the powder of $\mathrm{Cu}\left(\mathrm{F}_{8} \mathrm{Pc}\right)$, which was confirmed by elemental analysis (Calc. C, $53.38 \%$; $\mathrm{H}, 1.12 \%$; $\mathrm{F}$, 21.11\%; Cu, 8.83\%. Found: C, 52.74\%; H, 1.13\%; F, 21.03\%; $\mathrm{Cu}$, 9.17\%), (UV-vis (Chloronaphtalene): $Q$ band-664 $\mathrm{nm}$ ). The synthesis of $\mathrm{Cu}\left(\mathrm{Cl}_{8} \mathrm{PC}\right)$ was performed by refluxing a mixture of 4,5-dichlorophthalic anhydrid, copper (II) acetate tetrahydrate, urea and ammonium heptamolybdate in nitrobenzene for $5 \mathrm{~h}$. The detailed synthesis procedure is reported in our recent works. ${ }^{58}$ The obtained precipitate was filtered, washed (with ethanol and water) and treated with $10 \% \mathrm{HCl}$. The resulting solid was successively washed with toluene, ethanol, methanol and acetone to yield finally a blue coloured powder of $\mathrm{Cu}\left(\mathrm{Cl}_{8} \mathrm{Pc}\right)$, which elemental composition and structure were confirmed (Calc. C, 45.13; H, 0.95; N, 13.16; found: C, 44.1; H, 0.87; N, 13.21), (UV-vis (DMF): $Q$ band-632 and $701 \mathrm{~nm}$, aggregates). $\mathrm{Cu}\left(\mathrm{F}_{16} \mathrm{Pc}\right)$ was synthesized by heating the reaction mixture of tetrafluorophthalonitrile and copper(II) chloride at $250{ }^{\circ} \mathrm{C}$ for 7 hours based on the previously reported procedure (UV-vis (Chloronaphtalene): Q band-691 nm). ${ }^{59}$ The synthesis of $\mathrm{LuPC}_{2}$ was realized without any solvent between phthalonitrile and $\mathrm{Lu}(\mathrm{OAC})_{3} \cdot 3 \mathrm{H}_{2} \mathrm{O}$ in $8: 1$ ratio at $300{ }^{\circ} \mathrm{C} .{ }^{60}$ The reaction product was washed with DMF and ethanol to remove unreacted precursors and monophthalocyanines followed by drying at $100{ }^{\circ} \mathrm{C}$ to obtain $\mathrm{LuPc}_{2}$ powder, which elemental composition and structure was confirmed (UV-Vis Soret band $-320 \mathrm{~nm}$; Q band - $658 \mathrm{~nm}$, FTIR peaks at 722, 1123,1317 and $1449 \mathrm{~cm}^{-1}$ ).

\section{Devices fabrication and electrical measurements}

Heterojunction devices were fabricated on ITO interdigitated electrodes (IDE), lithographically patterned on a $(1 \times 1) \mathrm{cm}^{2}$ glass substrate and separated by $75 \mu \mathrm{m}$. The bilayer films of 50 $\mathrm{nm}$ each of MPc (except for $\mathrm{Cu}\left(\mathrm{Cl}_{8} \mathrm{Pc}\right): 30 \mathrm{~nm}$ ) were sequentially deposited on ITO IDE maintained at room temperature under secondary vacuum (ca. $10^{-6} \mathrm{mbar}$ ) in UNIVEX 250 thermal evaporator (Oerlikon, Germany). The sublimation temperature of MPcs were noted in the range of $400-480{ }^{\circ} \mathrm{C}$. No post deposition thermal or chemical treatment was performed. A similar size glass substrate was placed next to the IDE for further structural and morphological studies of the films. Electrical measurements of the fabricated devices were carried out using a Keithley electrometer in a bias voltage from $-10 \mathrm{~V}$ to $10 \mathrm{~V}$ by step of $0.1 \mathrm{~V}$ in ambient air. Impedance measurements of different heterojunction devices were performed using a Solartron SI 1260 impedance analyzer. The frequency range was $10 \mathrm{~Hz}$ to $10 \mathrm{MHz}$ with a fixed ac oscillation amplitude of $200 \mathrm{mV}$ and a DC bias ranging from $0 \mathrm{~V}$ to $10 \mathrm{~V}$. A commercial software Zview from Ametek was used for impedance data fitting and parameters extraction.

The workstation used for electrical measurements and $\mathrm{NH}_{3}$ sensing at different $\mathrm{rh}$ is shown in Scheme 2, consisting of fluidic circuits connected with commercial cylinders of synthetic air and ammonia gas (1000 ppm concentration, purchased from Air Liquide France). The flow in the circuit is controlled by electronic valves and the total flow was maintained in the range of $0.5-0.55 \mathrm{NL} \cdot \mathrm{min}^{-1}$ depending on ammonia concentration required in the sensors test chamber (of volume $8 \mathrm{~cm}^{3}$ ). The workstation was fully automated in which the gas flow, humidity, switching of the valves, data transfer and initiation of a new measurements were controlled by a homemade and customized software. Gas sensing experiments were carried out in a dynamic way through alternate exposure to $20 \mathrm{ppm}$ of $\mathrm{NH}_{3}$ and recovery under clean air for $1 \mathrm{~min}$ and $4 \mathrm{~min}$, respectively, at rh of $40 \%$. The sensors test chamber was integrated with 6 standard LEDs (green, yellow and red with maximum wavelength $565 \mathrm{~nm}, 594 \mathrm{~nm}$ $642 \mathrm{~nm}$, respectively), placed at the bottom of the test chamber at a distance of approximately $2 \mathrm{~cm}$ from the sensor. Continuous measurements were recorded for repeated exposure-recovery cycles at first in dark, then under LEDs illumination.

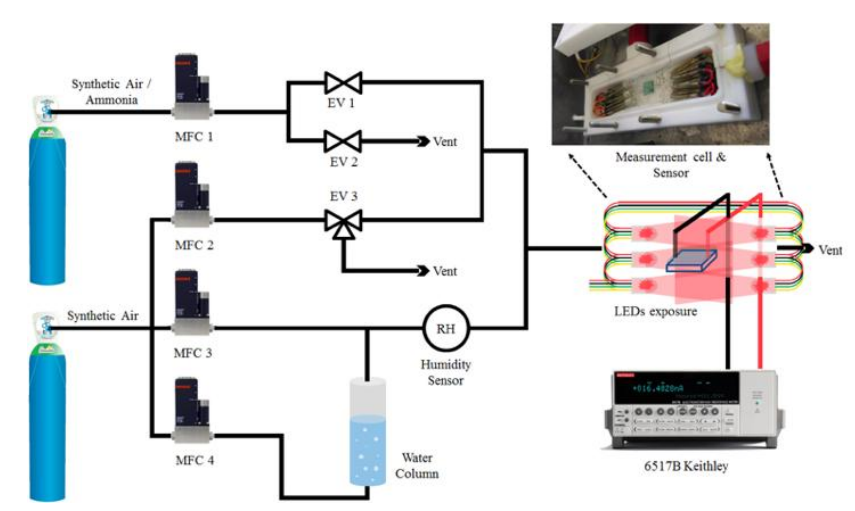


Scheme 2 Illustration of device testing workstation integrating gas sources, fluidic circuits, electronic valves, humidity generator, test chamber equipped with LEDs and electrometer

\section{Thin films characterizations}

The MPc films coated on glass substrates were studied by $X$ Ray diffraction (XRD) at room temperature using a PANanalytical X'pert MPD diffractometer with $\mathrm{Cu}-\mathrm{K}_{\alpha}$ incident radiation $\left(\lambda=1.5418 \AA\right.$ ) in the $2 \theta$ window of 5 to $80^{\circ}$, using a scan step of $0.05^{\circ}$. To evaluate the phase purity and spatial orientations, experimental data were fitted by profile matching in Fullprof software. The morphology of the MPc films coated on glass were analysed using a Scanning Electron Microscope (Quanta FEG 650, FEI equipped with an EDS detector), operating at accelerating voltage of 3-5 kV, while performing horizontal scan of the surface. A thin gold layer was at first sputtered on the film to establish electrical contact with the microscope and also to avoid over-charging of the film. EDX spectra and mapping of the different MPc films were also recorded.

\section{Conclusion}

In summary, we have demonstrated for the first time the application of visible wavelength photons produced by LED illumination, as an external trigger for the majority charge carrier inversion in an ambipolar organic heterojunction device. To achieve the ambipolar transport regime, a judicious selection among $\mathrm{p}$-type and $\mathrm{n}$-type halogenated $\mathrm{CuPc}$ has been made, which are combined with high conducting $\mathrm{LuPc}_{2}$ in a bilayer heterostructure configuration.

Thin film microstructural properties of the heterostructures revealed a compact and semicrystalline organization having predominantly an amorphous phase in which small pockets of crystallites are present, which sizes and orientations depended on the halogen substitution in CuPc. The I(V) curves of the heterojunction devices revealed a non-linear behavior consisting an energy barrier, which is largest for $\mathrm{Cu}\left(\mathrm{F}_{8} \mathrm{Pc}\right) / \mathrm{LuPc}_{2}$ and lowest for CuPc/LuPc$c_{2}$. The energy barrier is slightly decreased upon photon exposure which is attributed to generation of additional charge carriers, which were otherwise held in shallow traps. Under exposure to ammonia, $\mathrm{Cu}\left(\mathrm{F}_{8} \mathrm{Pc}\right)$ based heterojunction device exhibited p-type and n-type response in the dark and under LED illumination, respectively, while other heterojunction devices displayed only either of the two states, confirming ambipolar transport regime in $\mathrm{Cu}\left(\mathrm{F}_{8} \mathrm{Pc}\right) / \mathrm{LuPC}_{2}$ device, which is controlled uniquely by photons and remains independent of the bias voltage. Charge transport studies by impedance spectroscopy revealed a combination of bulk and interfacial transport in the heterojunction devices while only bulk transport exists in $\mathrm{LuPc}_{2}$ resistors. It is also confirmed that interfacial transport increases as a function of increasing bias voltage, which is associated with decrease of energy barrier at the interface. Fitting of the experimental Nyquists plots with two components R-CPE equivalent circuits allowed determination of different circuit parameters which were finally correlated with the charge transport in the devices. These parameters confirmed the generation of additional charge carriers in the bulk of $\mathrm{Cu}\left(\mathrm{F}_{8} \mathrm{Pc}\right) / \mathrm{LuPc}_{2}$ heterostructure upon photon exposure, changing its semiconducting polarity from $\mathrm{p}$ to $\mathrm{n}$-type.

\section{Author Contributions}

Gracia Loma: Investigation, Methodology and Visualization. Abhishek Kumar: Conceptualization, Investigation, Visualization, Data curation, Software, Formal analysis, Writing - original draft, Writing - review \& editing. Vaibhav Vibhu: Investigation, Methodology, Visualization, Data curation, Software, Formal analysis. Alix Deshotel: Investigation, Methodology and Visualization. Mickaël Mateos: Investigation, Methodology and Visualization. Seydou Ouedraogo: Investigation, Methodology and Visualization. Rita Meunier-Prest: Conceptualization, Formal analysis, Investigation, Methodology, Data curation, Validation. Marcel Bouvet: Conceptualization, Formal analysis, Visualization, Funding acquisition, Writing - original draft, Supervision, Validation, Project administration

\section{Conflicts of interest}

There are no conflicts to declare.

\section{Acknowledgements}

The authors acknowledge the Agence Nationale de la Recherche (OUTSMART ANR-2015-CE39-0004-03). This work was supported by the French "Investissements d'Avenir" program, project ISITE BFC (contract ANR 15 IDEX 0003) "Master T2MC" (G. L. K.) and CoMICS program 2019-2022 : Chemistry of Molecular Interactions - Catalysis and Sensors) (A. K.). Financial assistance from Conseil Régional de Bourgogne and European Union (FEDER) through the FABER and the CDEA program are gratefully acknowledged.

\section{Notes and references}

1 J. Cornil, J. L. Brédas, J. Zaumseil and H. Sirringhaus, Adv. Mater., 2007, 19, 1791-1799.

2 E. J. Meijer, D. M. de Leeuw, S. Setayesh, E. van Veenendaal, B. H. Huisman, P. W. M. Blom, J. C. Hummelen, U. Scherf and T. M. Klapwijk, Nat. Mater., 2003, 2, 678-682.

3 W.-J. Zeng, X.-Y. Zhou, X.-J. Pan, C.-L. Song and H.-L. Zhang, AIP Adv., 2013, 3, 012101, DOI: 10.1063/1.4774287.

4 M. Kang, D. Khim, J. Kim, H. J. Lee, J. Y. Jo, K.-J. Baeg and D.Y. Kim, Org. Electron., 2018, 58, 12-17.

5 Y. Zhou, S.-T. Han, P. Sonar and V. A. L. Roy, Sci. Rep., 2013, 3, 2319, DOI: 10.1038/srep02319.

6 X. Chen, J. Pan, J. Fu, X. Zhu, C. Zhang, L. Zhou, Y. Wang, Z. Lv, Y. Zhou and S.-T. Han, Adv. Electron. Mater., 2018, 4, 1800444, DOI: 10.1002/aelm.201800444. 
7 H. Kwon, H. Yoo, M. Nakano, K. Takimiya, J.-J. Kim and J. K. Kim, RSC Adv., 2020, 10, 1910-1916.

8 Y. Wu, P. Ma, N. Wu, X. Kong, M. Bouvet, X. Li, Y. Chen and J. Jiang, Adv. Mater. Interfaces, 2016, 3, 1600253, DOI: 10.1002/admi.201600253.

9 J. Gao, G. Lu, J. kan, Y. Chen and M. Bouvet, Sen. Actuators B, 2012, 166-167, 500-507.

10 A. Kumar, R. Meunier-Prest and M. Bouvet, Sensors, 2020, 20, 4700. DOI: 10.3390/s20174700.

11 M. Bouvet, Anal. Bioanal. Chem., 2006, 384, 366-373.

12 G. Bengasi, R. Meunier-Prest, K. Baba, A. Kumar, A. L. Pellegrino, N. D. Boscher and M. Bouvet, Adv. Electron. Mater., 2020, 2000812. DOI: 10.1002/aelm.202000812.

13 R. D. Gould, Coord. Chem. Rev., 1996, 156, 237-274.

14 M. Grobosch, C. Schmidt, R. Kraus and M. Knupfer, Org. Electron., 2010, 11, 1483-1488.

15 F. I. Bohrer, C. N. Colesniuc, J. Park, M. E. Ruidiaz, I. K. Schuller, A. C. Kummel and W. C. Trogler, J. Am. Chem. Soc., 2009, 131, 478-485.

16 L. S. Chia, Y. H. Du, S. Palale and P. S. Lee, ACS Omega, 2019, 4, 10388-10395.

17 S. Liu, H. Wang, X. Wang, S. Li, H. Liu, Y. Chen and X. Li, J. Mater. Chem. C, 2019, 7, 424-433.

18 X. Kong, Z. Dong, Y. Wu, X. Li, Y. Chen and J. Jiang, Chin. J. Chem., 2016, 34, 975-982.

19 A. Wannebroucq, S. Ouedraogo, R. Meunier-Prest, J.-M Suisse, M. Bayo and M. Bouvet, Sens. Actuators, B 2018, 258, 657-664.

20 X. Kong, X. Zhang, D. Gao, D. Qi, Y. Chen and J. Jiang, Chem. Sci., 2015, 6, 1967-1972.

21 D. Gao, X. Zhang, X. Kong, Y. Chen and J. Jiang, ACS Appl. Mater. Interfaces, 2015, 7, 2486-2493.

22 G. Lu, X. Kong, C. Wang, L. Zhao, D. Qi, Y. Jiang, S. Zhao, Y. Chen and J. Jiang, Dyes Pigm., 2019, 161, 240-246.

23 A. Dodabalapur, H. E. Katz, L. Torsi and R. C. Haddon, Science, 1995, 269, 1560-1562.

24 A. Dodabalapur, H. E. Katz, L. Torsi and R. C. Haddon, Appl. Phys. Lett., 1996, 68, 1108-1110.

25 H. Wang and D. Yan, NPG Asia Mater., 2010, 2, 69-78.

26 A. Opitz, A. Wilke, P. Amsalem, M. Oehzelt, R.-P. Blum, J. P. Rabe, T. Mizokuro, U. Hörmann, R. Hansson, E. Moons and N. Koch, Sci. Rep., 2016, 6, 21291, DOI: 10.1038/srep21291.

27 S. Nénon, D. Kanehira, N. Yoshimoto, F. Fages and C. VidelotAckermann, Synth. Met., 2011, 161, 1915-1920.

28 K. Eguchi, M. M. Matsushita and K. Awaga, J. Phys. Chem. C, 2018, 122, 26054-26060.

29 B. Wang, T.-P. Huynh, W. Wu, N. Hayek, T. T. Do, J. C. Cancilla, J. S. Torrecilla, M. M. Nahid, J. M. Colwell, O. M. Gazit, S. R. Puniredd, C. R. McNeill, P. Sonar and H. Haick, Adv. Mater., 2016, 28, 4012-4018.

30 S. Ouedraogo, R. Meunier-Prest, A. Kumar, M. BayoBangoura and M. Bouvet, ACS Sens., 2020, 5, 1849-1857.

31 H. Tang, Y. Li, R. Sokolovskij, L. Sacco, H. Zheng, H. Ye, H. Yu, X. Fan, H. Tian, T.-L. Ren and G. Zhang, ACS Appl. Mater. Interfaces, 2019, 11, 40850-40859.

32 V. Parra, M. Bouvet, Semiconductor Transducer and Its Use in a Sensor for Detecting Electron-donor or ElectronAcceptor Species. U.S. Patent 8,450,725 B2, 28 May 2013.

33 N. T. Boileau, O. A. Melville, B. Mirka, R. Cranston and B. H. Lessard, RSC Adv., 2019, 9, 2133-2142.

34 H. Jiang, P. Hu, J. Ye, Y. Li, H. Li, X. Zhang, R. Li, H. Dong, W. $\mathrm{Hu}$ and C. Kloc, Adv. Mater., 2017, 29, 1605053, DOI: 10.1002/adma.201605053.
35 G. Guillaud, M. Al Sadoun, M. Maitrot, J. Simon and M Bouvet, Chem. Phys. Lett., 1990, 167, 503-506.

36 H. Alves, A. S. Molinari, H. Xie and A. F. Morpurgo, Nat Mater., 2008, 7, 574-580.

37 A. K. Debnath, A. Kumar, S. Samanta, R. Prasad, A. Singh, A. K. Chauhan, P. Veerender, S. Singh, S. Basu, D. K. Aswal and S. K. Gupta, Appl. Phys. Lett., 2012, 100 (14), 142104, DOI: 10.1063/1.3699272

38 H. Jiang, J. Ye, P. Hu, F. Wei, K. Du, N. Wang, T. Ba, S. Feng and C. Kloc, Sci. Rep., 2014, 4 (1), 7573, DOI: 10.1038/srep07573.

39 A. Sukhikh, D. Bonegardt, D. Klyamer, P. Krasnov and T. Basova, Molecules, 2020, 25 DOI: 10.3390/molecules25071620.

40 J. T. E. Quinn, J. Zhu, X. Li, J. Wang and Y. Li, J. Mater. Chem. C, 2017, 5, 8654-8681.

41 S. Senthilarasu, Y. B. Hahn and S.-H. Lee, J. Applied Physics, 2007, 102, 043512, DOI: 10.1063/1.2771046.

42 W. Chen, S. Chen, H. Huang, D. C. Qi, X. Y. Gao and A. T. S. Wee, Appl. Phys. Lett., 2008, 92, 063308, DOI: 10.1063/1.2857460.

43 J. E, S. Kim, E. Lim, K. Lee, D. Cha and B. Friedman, Appl. Surf. Sci., 2003, 205, 274-279.

44 P. A. Pandey, L. A. Rochford, D. S. Keeble, J. P. Rourke, T. S. Jones, R. Beanland and N. R. Wilson, Chem. Mater., 2012, 24 1365-1370.

45 M. Mateos, M.-D. Tchangaï, R. Meunier-Prest, O. Heintz, F. Herbst, J.-M. Suisse and M. Bouvet, ACS Sens., 2019, 4, 740747.

46 M. Bouvet, V. Parra and J. M. Suisse, Eur. Phys. J. Appl. Phys., 2011, 56, 34103, DOI: 10.1051/epjap/2011110220.

47 A. Litke, E. J. M. Hensen and J. P. Hofmann, J. Phys. Chem. C, 2017, 121, 10153-10162.

48 P. Gaudillat, A. Wannebroucq, J.-M. Suisse and M. Bouvet, Sens. Actuators, B, 2016, 222, 910-917.

49 B. Hirschorn, M. E. Orazem, B. Tribollet, V. Vivier, I. Frateur and M. Musiani, Electrochim. Acta, 2010, 55, 6218-6227.

50 K. A. Miller, R. D. Yang, M. J. Hale, J. Park, B. Fruhberger, C. N. Colesniuc, I. K. Schuller, A. C. Kummel and W. C. Trogler, J. Phys. Chem. B, 2006, 110, 361-366.

51 K. M. Lau, J. X. Tang, H. Y. Sun, C. S. Lee, S. T. Lee and D. Yan, Appl. Phys. Lett., 2006, 88, 173513, DOI: 10.1063/1.2198484.

52 R. Murdey, N. Sato and M. Bouvet, Mol. Cryst. Liq. Cryst., 2006, 455, 211-218.

53 R. Murdey, M. Bouvet, M. Sumimoto, S. Sakaki and N. Sato, Synth. Met., 2009, 159, 1677-1681.

54 H. Wang and D. Yan, NPG Asia Mater., 2010, 2, 69-78.

55 P. K. Nayak, R. Rosenberg, L. Barnea-Nehoshtan and D. Cahen, Org. Electron., 2013, 14, 966-972.

56 X. Zhang, J. Jie, Z. Wang, C. Wu, L. Wang, Q. Peng, Y. Yu, P. Jiang and C. Xie, J. Mater. Chem., 2011, 21, 6736-6741.

57 V. Parra, J. Brunet, A. Pauly and M. Bouvet, Analyst, 2009, 134, 1776-1778.

58 S. Ouedraogo, T. Coulibaly, R. Meunier-Prest, M. BayoBangoura and M. Bouvet, J. Porphyrins and Phthalocyanines, 2019, 24, 750-757.

59 J. M. Birchall, R. N. Haszeldine and J. O. Morley, J. Chem. Soc. C, 1970, 2667-2672, DOI: 10.1039/J39700002667.

60 G. Clarisse and M. T. Riou, Inorg. Chim. Acta, 1987, 130, 139144. 